\title{
FONTES DE GORDURA SOBRE A MODULAÇÃO DO PERFIL DE ÁCIDOS GRAXOS DA CARNE DE PEQUENOS RUMINANTES
}

\author{
LIPID SOURCES ON MODULATION OF FATTY ACID PROFILE OF SMALL RUMINANTS \\ MEAT
}

Urbano, S. A. ${ }^{1 *}$; Ferreira, M. A. ${ }^{1}$; Oliveira, J.P.F. ${ }^{1}$; Lima Júnior, D.M. ${ }^{2}$ e Andrade, R.P.X. ${ }^{1}$

1Universidade Federal Rural de Pernambuco. Dois irmãos. Recife-PE. Brasil. “stela_antas@yahoo.com.br ${ }^{2}$ Universidade Federal de Alagoas. Alagoas. Brasil.

\section{PaLAVRAS ChaVE ADICIONAIS}

Biohidrogenação. Carne caprina. Carne ovina. CLA. Gordura saturada. Suplementação lipídica.

\section{RESUMO}

O metabolismo dos lipídios nos ruminantes envolve processos que modificam substancialmente os lipídios da dieta, sendo parcialmente responsáveis pela presença de grandes quantidades de ácidos graxos saturados na carne destes animais, bem como pela presença de CLA. Diante da preocupação do consumidor atual com aspectos concernentes à saúde, a ciência animal tem buscado manipular o perfil lipídico da carne de pequenos ruminantes objetivando enriquecê-la com ácidos graxos poliinsaturados, diminuir a relação saturado/insaturado e aumentar os teores de CLA. A dieta tem sido apontada como principal fator que influencia o perfil lipídico da carne de ruminantes. A literatura sugere que a suplementação com lipídios ricos em ácidos graxos poli-insaturados é eficiente em diminuir os ácidos graxos saturados e aumentar os teores de ácidos poli-insaturados benéficos à saúde humana. Fatores como relação volumoso : concentrado, fonte lipídica usada na suplementação, proteção da gordura e tempo de suplementação têm influência significativa sobre o efeito da inclusão de lipídios na alimentação de pequenos ruminantes. As sementes oleaginosas e seus respectivos óleos têm se mostrado eficientes em incrementar os teores de ácidos graxos poli-insaturados e CLA na carne de caprinos e ovinos. Oóleo de peixe e extrato de algas marinhas são fontes eficazes para maior deposição

\section{Additional KeYWORds}

Biohydrogenation. Goat meat. Lamb meat. CLA. Saturated fat. Lipid suplementation.

de ácidos graxos poli-insaturados de cadeia muito longa na carne. São necessárias mais pesquisas que investiguem como a dieta, e mais precisamente os lipídios, modulam os processos que ocorrem em nível de rúmen e modificam o perfil lipídico da carne de caprinos e ovinos.

\section{SUMMARY}

The lipid metabolism in ruminants involves processes which modify substantially the lipids in the diet. It is partly responsible for the presence of large amounts of saturated fatty acid in the meat of these animals, as well as by the presence of CLA. The modern consumer is concerned about the health aspects, thereby animal science has sought to manipulate the lipid profile of meat from small ruminants aiming to enrich it with polyunsaturated fatty acids, decrease the ratio saturated/unsaturated and increase the levels of CLA. The diet has been identified as the main factor influencing the lipid profile of ruminant meat. The literature suggests that supplementation with lipids rich in polyunsaturated fatty acids is effective in decreasing the saturated fatty acids and increase the levels of polyunsaturated acids beneficial to human health. Factors such as the forage : concentrate ratio, lipid source used in supplementation, protected fat and supplementation 
time have significant influence on the effect of inclusion of lipids in the diet of small ruminants. Oilseeds and their oils have been shown to be effective in increasing the levels of polyunsaturated fatty acids and CLA in meat goats and sheep. Fish oil and seaweed extract supplies are effective to increase the level of polyunsaturated fatty acids of very long chain meat. Fish oil and marine algae extract are effective sources for increasing polyunsaturated fatty acids of very long chain in meat. More research is needed to investigate how diet modulates the processes occurring in the rumen and modify the lipid profile of small ruminant's meat.

\section{INTRODUÇÃO}

Todos os vertebrados necessitam de uma quantidade mínima deácidos graxos essenciais para a sobrevivência, boa saúde e desempenho adequado, uma vez que os mesmos são utilizados como componentes das membranas celulares e como precursores das moléculas regulatórias do metabolismo. Os animais ruminantes são pouco tolerantes a teores elevados de gordura, o consumo de lipídios por estes animais é limitado na natureza, com as dietas contendo aproximadamente 2 a $3 \%$ de ácidos graxos, os quais são suficientes para suprir as exigências destes animais (Palmquist e Mattos, 2006; Dias et al., 2009).

Gorduras e óleos têm sido amplamente utilizados na nutrição de ruminantes com o intuito de aumentar a densidade energética da dieta e a eficiência alimentar (Valinote et al., 2005), constituindo uma importante ferramenta para contornar situações em que o consumo de alimentos é comprometido, como confinamento de animais em ambientes de altas temperaturas, ou na nutrição pós-parto de vacas lactantes de alta produção, por exemplo. Ainda, a utilização de lipídios na alimentação de ruminantes tem sido pesquisada com o objetivo de manipular a composição da fração gordurosa da carne e do leite, tendo em vista a grande preocupação do consumidor atual com os aspectos concernentes à saúde, que acabaram prejudicados pela dieta moderna (Lima Jr. et al., 2011).

Contudo, a inclusão de lipídios em níveis superiores a $5 \%$ (com base na matéria seca) está relacionada a alterações nos padrões de fermentação ruminal (Cenkvàri et al., 2005; Palmquist e Mattos, 2006). Os ingredientes utilizados na nutrição animal contêm grandes proporções de ácidos graxos poli-insaturados: fosfolipídios e glicolipídios presentes nas forragens e triglicerídeos presentes em grãos (Van Soest, 1994). Estes são tóxicos aos micro-organismos ruminais, sobretudo às bactérias Gram-positivas e aos protozoários, por causarem rompimento da membrana celular microbiana e prejudicarem a função celular e a atividade das enzimas hidrolíticas bacterianas. Os ácidos graxos podem ainda aderir à partícula do alimento criando uma barreira física à ação de micro-organismos e enzimas microbianas, prejudicando a degradação do alimento (Jenkins, 1993; Balieiro Neto e Melloti, 2007).

Os estudos sobre metabolismo lipídico no rúmen têm se concentrado na manipulação dos fenômenos físico-químicos do rúmen, objetivando principalmente: controlar os efeitos antimicrobianos dos ácidos graxos, de forma que a suplementação com gordura possa ser empregada na alimentação de ruminantes sem prejuízo da digestão e da fermentação ruminal; e regular a biohidrogenação microbiana, para controle da absorção de determinados ácidos graxos que podem promover melhor desempenho e/ou reduzir a saturação da gordura da carne e do leite (Jenkins, 1993).

A revisão que segue trata dos efeitos de diferentes fontes de lipídios sobre o perfil de ácidos graxos da carne, pontuando as particularidades dos processos de digestão de lipídios em ruminantes.

\section{O PERFIL LIPÍDICO DA CARNE DE PEQUENOS RUMINANTES E SUA RELAÇÃO COM A SAÚDE HUMANA}

Apesar de a carne vermelha ser cientificamente comprovada como fonte de proteína de alto valor biológico (Valsta et al., 2005), aminoácidos essenciais e boas quantidades 
de minerais e vitaminas (Ferguson, 2010), a gordura é o constituinte mais popular da carne, sendo responsável pela rotulagem da mesma como produto prejudicial à saúde (Webb e O’Neill, 2008; Wood et al., 2008), o que tem afetado o consumo de carne e respectivos subprodutos em alguns países (Bas et al., 2007).

O interesse pela saúde e pela qualidade de vida caracteriza o consumidor do século XXI, que tem consciência de que muito embora a alimentação não seja o único fator que afeta a saúde, ela é, certamente, um dos mais importantes. Desse modo, alguns aspectos causam desconfiança por parte do consumidor, um deles é a implicação de certos constituintes da carne em algumas das doenças mais prevalecentes na sociedade moderna (doenças cardiovasculares, câncer, hipertensão e obesidade) (Colmenero et al., 2001). De fato, a quantidade e a qualidade da gordura ingerida estão fortemente relacionadas à saúde humana (Rioux e Legrand, 2007).

A gordura dos depósitos adiposos de animais ruminantes é rica em triglicerídios, com predomínio de ácidos graxos saturados e pouca quantidade de poli-insaturados (Mahgoub et al., 2002; Bas et al., 2007). Normalmente, $80 \%$ dos ácidos graxos são C14:0, C16:0, C18:0 e C18:1. Estão presentes ainda isômeros trans/cis de ácidos graxos insaturados, ácidos de cadeia ímpar e ramificada. Este perfil lipídico é reflexo das transformações e síntese microbianas de lipídios que ocorrem em nível de rúmen (Church, 1993). Há que se considerar ainda, que o metabolismo ruminal é também responsável pelo fato de os animais ruminantes serem os principais fornecedores de isômeros de ácido linoléico conjugado (CLA) à dieta humana (Bessa et al., 2000; Schmid et al., 2006; Lima Jr. et al., 2011).

$\mathrm{Na}$ dieta humana, o consumo de ácidos graxos saturados em um teor superior a $15 \%$ da energia dietética diária está correlacionado com aumento nos níveis sanguíneos de colesterol e diminuição da atividade dos receptores LDL-colesterol, que conduzem a quadros de doenças cardíacas coronarianas (Rioux e Legrand, 2007). Os ácidos palmítico (C16:0) e mirístico (C14:0) elevam os níveis sanguíneos de lipoproteínas de baixa densidade (LDL-colesterol). O ácido láurico (C12:0) promove hipercolesterolemia, sendo em menor quantidade que os ácidos palmítico e mirístico (Lima et al., 2000).

Alguns autores citam que os ácidos graxos monoinsaturados não influenciam nos níveis de colesterol (Lima et al., 2000), mas quando substituem os ácidos graxos saturados da dieta podem reduzir as taxas de colesterol plasmático (Santos Filho et al., 2001). Ainda, estudos de população têm revelado associação negativa entre a ingestão de ácidos graxos mono e poli-insaturados e a incidência de doenças cardiovasculares, bem como uma associação com efeitos benéficos nas concentrações de LDL e HDL-colesterol (Jonnalagada et al., 1996).

No grupo dos ácidos graxos poli-insaturados duas famílias têm se destacado na abordagem alimentos $x$ saúde: ácidos graxos ômega 3 (n-3 ou $\omega$-3) e ômega 6 (n-6 ou $\omega-6$ ), principalmente representados pelos ácidos linolênico (C18:3 n-3) e linoléico (C18:2 n-6), respectivamente. Eles não podem ser sintetizados pelas células animais e são essenciais ao organismo por serem precursores dos ácidos graxos de cadeia longa, desse modo, devem ser providos ao organismo via dieta (Herdmann et al., 2010). Os $\omega$-3 são precursores dos ácidos eicosapentaenóico (EPA) e decosahexaenóico (DHA), os quais estão envolvidos na prevenção de doenças cardiovasculares e da hipertensão por inibirem a síntese de triglicerídios em nível hepático. $\mathrm{O}$ DHA está ainda relacionado à função visual e cerebral (Gibson e Makrides, 2000). Já os $\omega$-6 são precursores das prostaglandinas e leucotrienos, muito importantes na regulação do metabolismo hormonal que inclui a síntese do colesterol(Anjo, 2004). Contudo, para síntese dos seus derivados os $\omega-3$ e $\omega-6$ utilizam as mesmas enzimas, sendo a ordem de preferência dos substratos pelas enzimas: ômega-3 > 
ômega-6 > ômega-9 (Lima Jr. et al., 2011), o que traz grande importância ao equilíbrio da proporção destes ácidos graxos na dieta. Para garantir uma produção equilibrada de eicosanoides, Herdmann et al. (2010) citaram que a relação $\omega-6: \omega-3$ deve estar entre $4: 1$ e $6: 1$.

Ainda no grupo dos poli-insaturados, outros ácidos graxos apresentam relevada importância à saúde humana: os CLAs (Herdmann et al., 2010). O termo CLA descreve um conjunto de isômeros geométricos do ácido linoléico com propriedades bioativas distintas, que têm duas duplas ligações separadas por apenas uma ligação simples (insaturação conjugada). A conjugação da dupla ligação é geralmente nas posições 9 e 11 ou 10 e 12, podendo apresentar configuração geométrica nas formas cis-cis, cis-trans, trans-cis e trans-trans, sendo que as formas biologicamente mais ativas são os isômeros C18:2 cis-9, trans-11 (Abu-Ghazaleh et al., 2001). O CLA origina-se da isomerização e/ou biohidrogenação bacteriana de ácidos graxos poli-insaturados e da dessaturação de ácidos graxos trans no tecido adiposo por atividade da $\Delta-9$ dessaturase, muito embora esta última via seja mais expressiva na glândula mamária, contribuindo pouco para a síntese de CLA no tecido adiposo. Dentre algumas propriedades do CLA destacam-se as anticarcinogênicas e antioxidantes, além do efeito sobre doenças cardiovasculares, diabetes e sistema imune (Blankson et al., 2000; Bessa et al, 2000). Tem sido sugerido ainda que o CLA modula o metabolismo lipídico por inibir a lipogênese e aumentar a lipólise (Bessa et al., 2000; Marinova et al., 2001). Embora os dados derivem de testes em animais e não sejam conclusivos para humanos, os resultados são animadores (Schmid et al., 2006).

Diante do contexto carne $x$ saúde, a quantidade e qualidade da gordura são responsáveis em tornar, ou não, a carne um alimento saudável. Assim, a composição química da carne de pequenos ruminantes-sobretudo dos caprinos - com teores reduzidos de gordura (Madruga et al., 2001; Mahgoub et al., 2002; Mushi et al. 2012) quando comparada à carne de outras espécies, tem atraído novos consumidores. Apesar de sofrer grande influência de fatores como espécie, raça, sexo, nutrição e peso ao abate (Bonagurio et al. 2004), o teor médio de gordura da carne de ovinos é de $4 \%$ (Zeola et al., 2004); já a carne caprina sofre as mesmas influências, mas apresenta teores médios que variam entre 2 e $3 \%$ (Nassu et al., 2002).

Alguns ácidos graxos sempre aparecem em maiores quantidades nas carnes de pequenos ruminantes. Em ovinos, os ácidos oleico, palmítico e esteárico destacam-se dos demais (Zapata et al., 2001; Madruga et al., 2006). Banskalieva et al. (2000) fizeram a mesma inferência para a carne de caprinos, destacando que os percentuais podem estar entre 28 e $50 \%$ para $\mathrm{C} 18: 1 ; 15$ e $31 \%$ para C16:0; e 6 e $17 \%$ para C18:0. De fato, Gaili e Ali (1985) afirmaram há tempos que estes três ácidos graxos poderiam compor $90 \%$ do perfil lipídico da carne de ruminantes. Em ambas as espécies os ácidos graxos monoinsaturados aparecem em maior quantidade que os ácidos graxos poliinsaturados (Tshabalala et al., 2003), e estes estão presentes em pequenas quantidades, já que no músculo e no tecido adiposo destes animais os ácidos graxos poli-insaturados, sobretudo os de cadeia longa, estão restritos quase que exclusivamente, à fração fosfolipídica (Wood et al., 2004). Todavia, alguns fatores podem influenciar o perfil lipídico da carne de pequenos ruminantes: raça, sexo, peso ao abate, ambiente, alimentos, alimentação e as interações entre os mesmos são os principais (Wood et al., 2004; Woods e Fearon, 2009).

Demirel et al. (2006) evidenciaram que a genética tem grande influência sobre o perfil de ácidos graxos da carne. Hoffman et al. (2003) estudaram seis diferentes cruzamento em ovinos e verificaram influência da raça sobre os ácidos graxos monoinsaturados totais eácidos graxos saturados totais. Maia et al. (2012) avaliaram seis genótipos ovinos e observaram influência dos mesmos sobre a concentração de ácidos graxos monoinsaturados totais. Madruga et al. (2006) compararam o perfil 
lipídico da carne de machos da raça Santa Inês e machos cruzados Santa Inês x Dorper, os autores verificaram maior percentual de ácidos graxos monoinsaturados na carne dos ovinos puros, enquanto o percentual de ácidos graxos poli-insaturados foi maior na carne dos ovinos cruzados.

Banskalieva et al. (2000) reportaram que diferenças na composição de ácidos graxos entre animais de sexos diferentes têm sido inconsistentes. Madruga et al. (2006) relataram maior teor de C18:1 na carne de fêmeas ovinas quando comparada aos machos do mesmo genótipo, não havendo, contudo, influência sobre as concentrações totais de ácidos graxos saturados, monoinsaturados e poli-insaturados. Já Tejeda et al. (2008) verificaram que fêmeas apresentaram maiores concentrações de ácidos graxos poli-insaturados que os machos. Avaliando caprinos mestiços em diferentes condições sexuais, Madruga et al. (2001) relataram maiores concentrações totais de ácidos graxos saturados, insaturados e poliinsaturados na carne de animais emasculados quando comparados aos intactos.

No que diz respeito ao peso ao abate, não há consenso sobre o efeito no perfil de ácidos graxos da carne. Perez et al. (2002) avaliaram o perfil lipídico da carne de ovinos da raça Bergamácia abatidos com 15, 25, 35 e 45 de peso corporal e verificaram que as concentrações do ácido palmítico e do ácido oléico, bem como o somatório dos ácidos graxos monoinsaturados e poli-insaturados, elevaram-se com o aumento do peso ao abate. No mesmo ensaio experimental, já não foram obtidos resultados semelhantes para ovinos da raça Santa Inês. Tejeda et al. (2008) avaliaram o perfil de ácidos graxos de ovinos da raça Merino abatidos aos 24 e 29 kg e não verificaram efeito do peso ao abate no somatório de ácidos graxos saturados, monoinsaturados e poli-insaturados.

Apesar dos relatos acima, a dieta tem sido apontada como principal fator que influencia o perfil de ácidos graxos da carne (Wood et al., 2004). Embora seja mais eficiente em animais monogástricos pela ausência do metabolismo ruminal, a manipulação do perfil de ácidos graxos da carne de ruminantes pela dieta é uma realidade no estudo da nutrição animal (Wood et al., 1999).

Madruga et al. (2008a) avaliaram o perfil de ácidos graxos da carne de caprinos da raça Saanen alimentados com diferentes níveis de concentrado e detectaram influência das dietas em alguns ácidos, inclusive nos ácidos palmítico e oleico, que se destacam no perfil lipídico da carne de pequenos ruminantes. Houve influência também nos totais de ácidos graxos mono e poli-insaturados. Com base nas relações entre os ácidos graxos, os autores afirmaram que não houve efeito da dieta sobre a qualidade lipídica da carne caprina. Demirel et al. (2006) alimentaram dois grupos de ovinos com diferentes relações volumoso: concentrado e verificaram efeito sobre o perfil de ácidos graxos da carne, evidenciando a influência nos teores de $\omega-3$ e $\omega-6$, como mostra a tabela I.

Nuernberg et al. (2008) mantiveram dois grupos de ovinos em sistemas de alimentação diferentes: forragem + concentrado; apenas forragem. Os autores reportaram maior concentração de CLA (cis-9, trans-11) na carne dos ovinos que consumiram apenas forragem, além de uma menor relação $\omega-6 / \omega-3$ para o mesmo grupo. Aurousseau et al. (2004) verificaram o mesmo comportamento para teores de CLA e relação $\omega-6 / \omega-3$ na carne de ovinos alimentados com dieta a base de forragem, quando comparados a ovinos que consumiram dieta a base de grãos.

Além da relação volumoso : concentrado, outros aspectos concernentes à alimentação podem ter influência direta sobre o perfil de ácidos graxos da carne. Santos-Silva et al. (2004), por exemplo, relataram o efeito do tamanho da partícula de alimento sobre o perfil de ácidos graxos da carne de ovinos. Outros autores avaliaram o efeito da inclusão de certos ingredientes sobre a composição lipídica da carne, como a farinha de peixe, a gordura protegida (Ponnampalam et al., 
Tabela I. Perfil de ácidos graxos da carne ( $\mathrm{mg} / 100 \mathrm{~g}$ músculo) de ovinos alimentados com diferentes relações volumoso: concentrado. (Fatty acid profile of the meat (mg/ $100 \mathrm{~g}$ muscle) of sheep fed with different forage concentrated ratios).

\begin{tabular}{lccc}
\hline Ácido graxo & \multicolumn{2}{c}{ Grupo } & $\mathrm{p}$ \\
\cline { 2 - 3 } & $75 \mathrm{~V}: 25 \mathrm{C}$ & $25 \mathrm{~V}: 75 \mathrm{C}$ & $<0,001$ \\
C14:0 & 75,0 & 59,9 & $<0,001$ \\
C16:0 & 446 & 385 & $<0,001$ \\
C16:1 & 40,6 & 21,1 & $<0,001$ \\
C18:0 & 424 & 321 & $<0,001$ \\
C18:1 & 758 & 608 & $<0,001$ \\
C18:2n-6 & 96,6 & 190 & $<0,001$ \\
C18:3n-3 & 46,7 & 13,0 & $<0,001$ \\
C20:4 $n-6$ & 26,2 & 39,0 & $<0,001$ \\
C20:5n-3 & 25,4 & 10,8 & $<0,001$ \\
C22:5n-3 & 15,7 & 5,6 & $<0,001$ \\
C22:6n-3 & 7,8 & 3,0 & \\
\hline
\end{tabular}

Fonte: adaptado de Demirel et al. (2006).

2002a), o caroço de algodão (Madruga et al., 2008b), entre outros. Em suma, partindo do pressuposto que o metabolismo ruminal é responsável, em partes, pelo perfil lipídico da carne de ruminantes, supõe-se que tudo aquilo que pode interferir na fermentação ruminal tem capacidade de modificar o perfil lipídico da carne. Isto tem sido motivo para realização de inúmeras pesquisas, sobretudo daquelas que investigam o efeito da inclusão de diferentes fontes de lipídios na alimentação de ruminantes, que serão abordadas adiante.

\section{METABOLISMO LIPÍDICO RUMINAL}

Os micro-organismos ruminais modificam substancialmente os lipídios oriundos da dieta através de três processos sequenciais: hidrólise (lipólise), biohidrogenação e saponificação de ácidos graxos (Jenkins et al., 2008). As bactérias do rúmen podem ainda sintetizar ácidos graxos de cadeia longa, dependendo da quantidade de ácidos graxos consumidos (Kozloski, 2002; Relling e Mattioli, 2003).

Ao chegarem ao retículo-rúmen os lipídios esterificados presentes no alimento ingerido, compostos principalmente por triglicerídios, fosfolipídios e galactolipídios, precisam ser liberados da matriz do alimento através da degradação da parede celular, que ocorre por ação das bactérias celulolíticas. Em seguida, são hidrolisados extensivamente por lipases, galactosidases e fosfolipases microbianas, produzidas principalmente pela espécie bacteriana Anaerovibrio lipolytica e pelo gênero Butyrivibrio. Nos triglicerídeos, as ligações entre o glicerol e os ácidos graxos são quebradas liberando uma molécula de glicerol e três de ácidos graxos livres; nos fosfolipídios, a hidrólise leva à liberação de ácidos graxos e glicerofosfato; e nos galactolipídios, o processo gera ácidos graxos, galactose e glicerol (Kozloski, 2002; Wattiaux e Grummer, 2004; López e López, 2005; Palmquist e Mattos, 2006; Jenkins et al., 2008).

O glicerol é rapidamente fermentado em propionato e succinato (Palmquist e Mattos, 2006), enquanto os ácidos graxos insaturados liberados são biohidrogenados pelos microorganismos ruminais (Kozloski, 2002).

Alguns ácidos graxos, sobretudo os poliinsaturados, são tóxicos ás bactérias Grampositivas, metanogênicas e aos protozoários. Tal toxidade parece estar associada aos ácidos graxos que possuem maior solubilidade em água (anfifílicos) e membranas celulares, com potencial para romper a estrutura das 


\section{DIFERENTES FONTES DE GORDURA SOBRE A MODULAÇÃO DO PERFIL DE ÁCIDOS}

membranas. Neste sentido, durante o processo evolutivo a flora microbiana ruminal desenvolveu um mecanismo de autodefesa através do qual os ácidos graxos insaturados são convertidos em ácidos graxos saturados: a biohidrogenação (Palmquist e Mattos, 2006).

Além de ser justificado pela teoria da detoxificação, tem sido sugerido que o processo de biohidrogenação ocorre como mecanismo de eliminação de equivalentes redutores produzidos pela fermentação ruminal de carboidratos (Palmquist e Mattos, 2006; Maia, 2010), contudo, apenas 1 a $2 \%$ do hidrogênio metabólico é utilizado com este propósito (Jenkins, 1993).

A biohidrogenação não é um processo simples e ocorre em várias etapas pela ação bem descrito para o ácido linoléico e parcialmente conhecido para o $\alpha$-linolênico (figura 1), mas outros ácidos graxos não tiveram seu processo totalmente esclarecido (Leite, 2006; Palmquist e Mattos, 2006). Tomando o primeiro como exemplo, a primeira reação do processo corresponde a uma isomerização que converte o ácido linoléico (C18:2 cis-9, cis-12) em umácido linoleico conjugado(CLA)C18:2 cis-9; trans-11. Tal metabólito intermediário é rapidamente hidrogenado a C18:1 trans-11 por ação de uma redutase, sendo liberado no ambiente ruminal. Em seguida, ocorre mais uma hidrogenação, agora na ligação trans-11, formando o ácido esteárico (C18:0).

As bactérias que participam da biohidrogenação estão divididas em dois grupos:

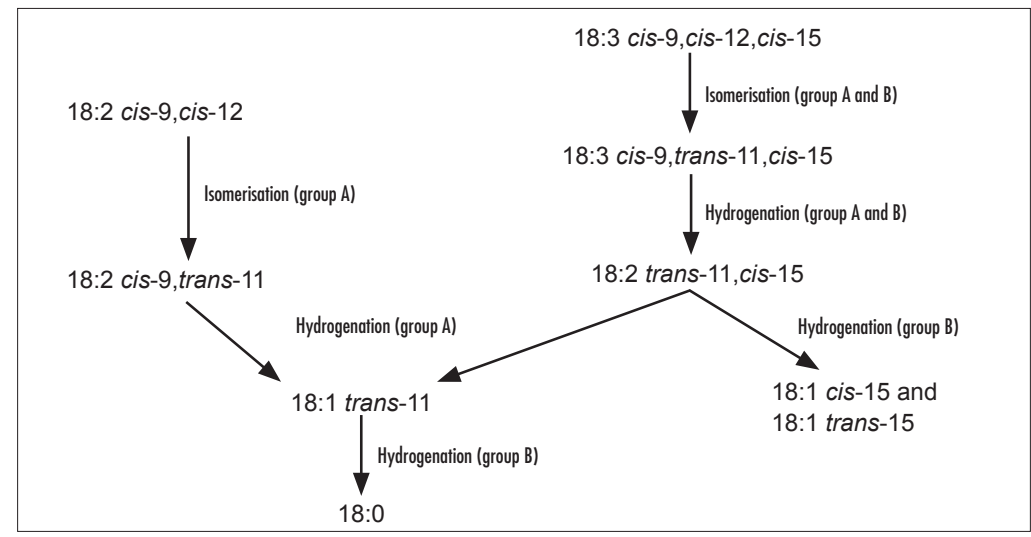

Figura 1. Vias de biohidrogenação do ácido linoléico (C18:2 cis-9, cis-12) e do ácido a-linolênico (C18:3 cis-9, cis-12, cis-15). (Routes of biohydrogenation of linoleic acid (C18: 2 cis-9, cis-12) and a-linolenic acid (C18: 3 cis-9, cis-12, cis-15)). Fonte: Maia (2010).

de isomerases e redutases, havendo formação de várias moléculas intermediárias (Leite, 2006). O processo não é completo, cerca de 70 a $90 \%$ dos ácidos graxos insaturados são hidrogenados, a pequena fração remanescente é incorporada aos lipídios bacterianos, tornando-se uma fonte de ácidos graxos essenciais e insaturados para o ruminante, quando absorvido no intestino delgado (Kozloski, 2002; Wattiaux e Grummer, 2004).

O processo de biohidrogenação ruminal é
A e B. As bactérias do grupo $A$ hidrogenam principalmente $\mathrm{C} 18: 3 \mathrm{n}-3$ e C18:2 n-6 a C18:1 trans-11, nenhum $\mathrm{C} 18: 1$ é reduzido a $\mathrm{C} 18: 0$ por bactérias deste grupo. A hidrogenação de C18:2 n-6 e C18:1 (cis-9 e trans-11) a C18:0 é feita pelas bactérias do grupo B. O grupo $A$ é representado pela Butyrivibrio fibrosolvens e o grupo $B$ é composto pelo gênero Fusocillus e pela Butyrivibrio proteoclasticus (Maia, 2010).

O percentual de hidrogenação está re- 
lacionado ao $\mathrm{pH}$ ruminal e à quantidade de ácidos graxos poli-insaturados que chegam ao rúmen: quanto mais baixo o $\mathrm{pH}$ ruminal, maior é a inibição do crescimento das bactérias responsáveis pelo processo, sobretudo daquelas que realizam o último passo (18:1 $\rightarrow 18: 0)$, gerando uma maior quantidade de metabólitos intermediários; quanto mais ácidos graxos insaturados, menor a proporção de biohidrogenação (Relling e Mattioli, 2003).

Além dos ácidos linoléico e $\alpha$-linolêico, outros ácidos graxos poli-insaturados que adentram no ecossistema ruminal são os de cadeia muito longa, como o C20:5 n-3 e o $\mathrm{C} 22: 6 \mathrm{n}-3$, presentes em maiores quantidades em óleos de peixes e algas marinhas, os quais são extensivamente biohidrogenados no rúmen. Contudo, o processo parece ser muito mais complexo e, até o presente, não há informação suficiente sobre os intermediários formados pelo metabolismo microbiano que permita estabelecer as vias de biohidrogenação de tais ácidos graxos (Leite, 2006; Maia, 2010).

A biohidrogenação é responsável, em partes, pela alta proporção de ácidos graxos saturados/insaturados presente no tecido adiposo dos ruminantes (Kozloski, 2002) e, consequentemente, pelo perfil de ácidos graxos característico da carne destes animais (Jekins et al., 2008). Contudo, modificações na alimentação animal (composição, quantidade, suplementação com lipídios) alteram o processo e podem resultar em mudanças no perfil de ácidos graxos intermediários, bem como mudanças no perfil da população microbiana. Tem sido discutido que a inibição da hidrólise e da biohidrogenação poderiam aumentar o teor de ácidos graxos poli-insaturados da carne, entretanto, concomitantemente a isto, nenhum intermediário do processo benéfico à saúde humana - leia-se CLAs e C18:1 trans-11-seria absorvido e transferido à carne de ruminantes (Maia, 2010).

Devido ao baixo $\mathrm{pH}$ do rúmen os ácidos graxos reagem com íons de cálcio e magnésio, formando sabões insolúveis de cálcio e magnésio, os quais são atóxicos. É na forma saponificada que 70 a $80 \%$ dos lipídios abandonam o rúmen (Relling e Mattioli, 2003; Palmquist e Mattos, 2006).

Os micro-organismos ruminais não armazenam lipídios como triglicerídeos, mas sintetizam suas membranas plasmáticas utilizando os ácidos graxos presentes no rúmen advindos da ração. Os ácidos graxos de membranas microbianas são altamente saturados (principalmente C18:0 e C16:0), mas tem-se observado também a síntese e incorporação em membranas de ácidos graxos de cadeia com número ímpar de carbono e ácidos graxos de cadeia ramificada, que não ocorrem naturalmente nos alimentos consumidos pelos animais. Os ácidos graxos microbianos são absorvidos e seguem a via metabólica dos demais ácidos graxos, fazendo-se, inclusive, presentes nos lipídios da carne e do leite. (Kozloski, 2002; Relling e Mattioli, 2003; Lópeze López, 2005; Palmquist e Mattos, 2006).

Ácidos graxos de cadeia ramificada surgem a partir da substituição do acetato pelo isobutirato, isovalerato e 2-metil-butirato na síntese microbiana de ácidos graxos. Do mesmo modo, ácidos graxos de cadeia ímpar são derivados de compostos semelhantes a eles, ou seja, o propionato e valerato, como precursores da síntese de ácidos graxos (Kennelly, 1996).

É sabido que as bactérias ruminais não sintetizam ácidos graxos poli-insaturados (Kozloski, 2002). Estes, quando presentes nos micro-organismos ruminais, são oriundos da incorporação de ácidos graxos pré-formados disponíveis no rúmen (Jenkins, 1993). Jenkins et al. (2008) citaram que os lipídios protozoários contém, proporcionalmente, mais ácidos graxos insaturados que as bactérias e que, portanto, os protozoários podem representar uma fonte muito importante de ácidos graxos poli-insaturados, CLA's e C18:1 trans-11 para incorporação na carne e no leite.

Aquantidade de ácidos graxos sintetizados pelas bactérias depende da quantidade que ingressa via dieta, diminuindo quando a oferta exógena é aumentada (Relling e Mattioli, 2003; Palmquist e Mattos, 2006), uma vezque 
os ácidos graxos dietéticos são incorporados aos lipídios celulares, inibindo a síntese de novo (Church, 1993). Os lipídios constituem de 10 a $15 \%$ da matéria seca bacteriana e, dos ácidos graxos totais, cerca de 15 a 20 \% são monoinsaturados (Kozloski, 2002).

\section{MODULAÇÃO DO METABOLISMO LIPÍDICO RUMINAL PELA DIETA COM EFEITO SOBRE O PERFIL LIPÍDICO DA CARNE}

Segundo Bessa et al. (2000), muitos fatores são conhecidos por afetar o padrão de fermentação ruminal, sobretudo a biohidrogenação. Entre eles estão a relação forragem : concentrado, o $\mathrm{pH}$ do rúmen, a utilização de ionóforos, o nível de lipídios inclusos na dieta e o tipo de lipídio utilizado.

O perfil lipídico da carne pode ser modificado pela manipulação da grande fermentação ruminal, ou seja, pela alteração das proporções de ácidos graxos voláteis (AGV) oriundos da fermentação de carboidratos, tendo em vista que os AGV são precursores de grande importância na síntese de lipídios em ruminantes. A relação molar de acetato, propionato e butirato varia de 75:15:10 a 40:40:20 de acordo com a dieta fornecida (Valadares Filho e Pina, 2006). Maiores concentrações de acetato são verificadas quando são fornecidas dietas à base de forragens, ao passo que dietas ricas em concentrados promovem redução da relação acetato : propionato (Nussio et al., 2006). Em caprinos e ovinos, uma menor relação acetato : propionato induz a deposição de ácidos graxos de cadeia ramificada, enquanto maiores proporções de acetato aumentam a deposição de ácidos graxos saturados, sobretudo do palmítico (Church, 1993). Neste sentido, pesquisas têm avaliado o efeito de ionóforos, como a monensina sódica, sobre o perfil lipídico da carne de ruminantes (Menezes et al., 2006), uma vez que uma das propriedades deste aditivo alimentar está relacionada à redução da relação acetato : propionato.

Além de interferir no perfil lipídico da carne de ruminantes pela proporção de AGV produzidos, dietas contendo alto grão e baixa fibra têm efeitos mais específicos sobre as taxas de lipólise e biohidrogenação (Beam et al., 2000). Parte deste efeito pode ser atribuída à queda do $\mathrm{pH}$ ruminal. Beam et al. (2000) verificaram inibição severa da lipólise em $\mathrm{pH}$ $\leq 6,0$. Griinari e Bauman (1999) relataram que o baixo $\mathrm{pH}$ do rúmen diminui a população de bactérias responsáveis pela formação do ácido esteárico. Já Petrova etal. (1994) inferiram que dietas com baixo volumoso e alto concentrado podem aumentar a taxa de passagem e assim diminuir a biohidrogenação dos ácidos graxos insaturados. De fato, quando alimentaram ovinos com proporções decrescentes de fibra (42,8 \% a 19,5\%) e proporções crescentes de amido (12,2\% a 35,7\%), Gerson et al. (1983) observaram que as taxas de lipólise e biohidrogenação foram reduzidas em aproximadamente $50 \%$. Salienta-se ainda que baixos teores de nitrogênio dietético e pequenos tamanhos de partícula da fibra também reduzem as taxas de lipólise e biohidrogenação (Gerson et al., 1983; Gerson et al., 1988), nesteúltimo caso, a aderência bacteriana às superfícies da partícula alimentar é dificultada e a taxa de passagem é aumentada, reduzindo o tempo de exposição à atividade microbiana (Buccioni et al., 2012).

$\mathrm{Na}$ realidade, a manipulação do ecossistema ruminal visando um perfil lipídico mais saudável tem um alto grau de complexidade. Wood et al. (1999) exemplificaram esta dificuldade ao afirmarem que quando alimentados com altos níveis de concentrado, os ruminantes produzem carnes com elevadas concentrações de C18:2 e ácidos da série $\omega-6$; já quando alimentados principalmente com forragens, ocorre uma mudança na população microbiana do rúmen com subsequente redução da hidrogenção dos ácidos graxos poli-insaturados, diminuindo a deposição de ácidos graxos saturados. Por outro lado, embora dietas forrageiras proporcionem maior deposição de $\omega-3$, a produção de ácidos graxos saturados é potencializada (maiores proporções de acetato) e a relação poli-insaturado : saturado 
torna-se desfavorável em termos nutricionais.

No que diz respeito à suplementação dietética com lipídios, Beam et al. (2000) reportaram que a quantidade de lipídios inclusos na dieta e a quantidade de duplas ligações no ácido graxo têm grande influência sobre as taxas de lipólise e biohidrogenação. Altas concentrações de lipídios alteram o padrão da biohidrogenação, causando uma mudança nos produtos finais que se acumulam no rúmen. Estes autores evidenciaram que concentrações elevadas de $\mathrm{C} 18: 2$ no rúmen podem interferir no segundo passo da hidrogenação $(\mathrm{C} 18: 1 \rightarrow$ C18:0), levando ao acúmulo do ácido oléico. Isto permite inferir que a quantidade de ácido linoléico provido via dieta é determinante no escape ruminal e fluxo duodenal de ácidos graxos insaturados.

Diante deste contexto, pesquisadores tem considerado que o aumento da oferta de ácidos linoléico via dieta é uma estratégia alimentar para enriquecer a gordura de ruminantes com CLA (Santos et al., 2001), já que o ácido linoléico é um dos mais importantes precursores. Fontes importantes deste precursor seriam óleos oriundos de cereais e sementes oleaginosas. Contudo, trabalhar na biohidrogenação é também muito importante para este enriquecimento, e uma maneira de se fazer isto seria controlando o processo enzimático que converte CLA em C18:1 trans-11 (Bessa et al., 2000). Partindo do mesmo princípio - de que parte dos ácidos graxos poli-insaturados fornecidos escapam da biohidrogenação - Cooper et al. (2004) e Elmore et al. (2005) também afirmaram que para aumentar os níveis de $\omega-3$ no tecido muscular de ruminantes uma estratégia seria provê-los na alimentação através de farinha de peixe, óleo de peixe e algas marinhas. Herdmann et al. (2010) reportaram que o fornecimento de fontes dietéticas de $\omega$-3 leva ao enriquecimento de $\omega-3$ nos tecidos de ruminantes. Chow et al. (2004) estudaram o efeito da inclusão de óleo de peixe na lipólise e biohidrogenação e concluíram que o ingrediente não tem influência sobre tais processos no C18:2 n-6 e/ou C18:3 n-3, contudo, verificaram que a saturação completa é inibida, resultando em menores quantidade de C18:0 e maiores quantidades de C18:2 trans-11, cis-15 e C18:1 trans-11 que fluem para o intestino delgado. Wasowska et al. (2006) sugeriram que a inclusão de óleo de peixe na dieta de ruminantes pode reduzir a taxa de isomerização inicial dos ácidos linoléico e linolênico.

Todavia, vale relembrar os dois principais eventos que caracterizam a problemática da suplementação lipídica na dieta de ruminantes: o efeito toxico dos ácidos graxos insaturados aos micro-organismos do rúmen; e a influência negativa de elevados tores de lipídios na digestibilidade da fibra alimentar. Engajados na resolução desta causa, alguns pesquisadores têm obtido resultados satisfatórios com a utilização daquilo que denominam gordura protegida. Este conceito envolve o tratamento de compostos proteico-lipídicos liofilizados com produtos químicos não-aldeídos, tratamento de compostos lipídicos liofilizados com proteínas de soro de leite e tratamentos de ácidos graxos com amônia ou aminas para a formação de acilaminas, todos com o objetivo de tornar os ácidos graxos insaturados quimicamente indisponíveis para a biohidrogenação (Palmquist e Mattos, 2006). Outra alternativa são os sais de cálcio de ácidos graxos, que não interferem na fermentação microbiana e são por isso chamados de gorduras inertes no rúmen (López e López, 2005), neles a taxa de biohidrogenação pode cair pela metade quando comparado às fontes tradicionais de ácidos graxos (Palmquist e Mattos, 2006). Outra forma de proteção da gordura está relacionada à inclusão de sementes oleaginosas na dieta, as quais são ricas em ácidos graxos poli-insaturados e fisicamente protegidas da biohidrogenação pelas cascas (Aferri et al., 2005). Wood et al. (2004) afirmaram que maiores concentrações de ácidos graxos poliinsaturados na carne de ruminantes poderiam ser alcançadas através da suplementação com sementes de linhaça. Dessa forma, estratégias outrora desenvolvidas com intuito de inibir os 
efeitos adversos da suplementação lipídica são hoje coadjuvantes na manipulação do metabolismo lipídico ruminal que visa estabelecer uma relação mais saudável entre ácidos graxos saturados e insaturados nos tecidos de animais ruminantes.

Aliteratura aborda ainda outras substâncias capazes de influenciar a lipólise e biohidrogenação. Valsta et al. (2009) citaram que substâncias polifenólicas como os taninos podem reduzir a biohidrogenação porque inibem a atividade dos micro-organismos, além de ter atuação seletiva sobre as cepas bacterianas. Por motivo semelhante, Fellner et al. (1997) destacaram que a monensina sódica tem efeito sobre a lipólise e a biohidrogenação. Wang et al. (2005) conduziram um ensaio de fermentação in vitro e verificaram decréscimo na concentração de C18:0 e incremento no C18:1 n-9, C18:2 n-6, CLA cis-9, trans-11 e CLA trans-10 , cis-12 quando adicionaram monensina à solução. Os autores observaram ainda que estes efeitos foram potencializados com a inclusão da monensina associada ao óleo de peixe na solução de cultura.

A tentativa de modulação do metabolismo lipídico em ruminantes retrata a complexidade e a dinâmica do ecossistema ruminal. Se evitar a biohidrogenação pode levar ao incremento da concentração de ácidos graxos poli-insaturados como os $\omega$-3 e $\omega$ - 6 nos tecidos de ruminantes, preservar a biohidrogenação incompleta tende a aumentar os teores de CLA nos mesmos tecidos (Neves, 2007). Tais questionamentos somados à importância da reforma do perfil lipídico da carne de ruminantes que chega ao consumidor moderno instigam o refinamento de pesquisas que abordam esta problemática.

\section{EFEITOS DE DIFERENTES FONTES DE LIPÍDIOS NO PERFIL DE ÁCIDOS GRAXOS DA CARNE DE PEQUENOS RUMINANTES}

Além de uma menor ingestão total de gordura, os nutricionistas humanos têm reco- mendado uma maior ingestão de ácidos graxos poli-insaturados, especialmente os $\omega$ - 3 e $\omega$ - 6 . Buscando atender tais recomendações, os pesquisadores da ciência animal têm conduzido inúmeros ensaios com alimentação, nos quais o objetivo é trazer a relação poliinsaturado/ saturado da carne para mais perto do valor recomendado $(>0,7)$, além de buscarem equilibrar a relação $\omega-6 / \omega-3$ e incrementar os teores de isômeros CLA (Raes et al., 2004). Diante do que foi abordado sobre a transformação ruminal dos lipídios e seus efeitos no perfil de ácidos graxos da carne de pequenos ruminantes, esta seção visa reunir alguns ensaios realizados nos últimos anos, que utilizaram fontes diversas de lipídios na alimentação de pequenos ruminantes, objetivando atender as exigências do consumidor do século XXI.

Ivan et al. (2001) avaliaram a inclusão de óleo de semente de girassol na dieta de ovinos no teor de $6 \%$ da matéria seca. Não foram observadas diferenças para peso corporal final, ganho médio diário, conversão alimentar e peso de carcaça. Contudo, os autores obtiveram resultados interessantes em relação ao perfil lipídico da carne: redução da concentração de C16:0, C17:0 e C18:1; aumento nas concentrações de C18:2 e CLA; maior relação insaturado/saturado. Os resultados podem estar relacionados ao tipo de lipídio utilizado na suplementação. Neste caso, os autores inferiram que a composição do óleo de semente de girassol, rico em ácido linoléico, pode ter sido responsável pelo incremento nos teores de C18:2 e CLA. Em revisão, Raes et al. (2004) afirmaram que altos teores dietéticos de $\omega$-3 e ácido linoléico aumentam o conteúdo de CLA na carne de ruminantes. Outro resultado deste ensaio merece ser pontuado: além do perfil lipídico da carne, os autores avaliaram o efeito da suplementação sobre a fauna do rúmen e não detectaram a presença de protozoários no fluido ruminal dos os animais que foram suplementados com óleo. Este resultado evidencia o efeito tóxico dos lipídios insaturados aos protozoários do rúmen, sobretudo àqueles do grupo Holotrichia, que são considerados 
os mais sensíveis, seguidos pelos protozoários celulolíticos.

Segundo Rizzi et al. (2002), a eficiência do incremento de ácidos graxos poliinsaturados na carne de ruminantes através do fornecimento de sementes oleaginosas depende da proteção natural dessas sementes aos processos de fermentação no rúmen e também da composição lipídica dessas sementes. Partido desta hipótese, os autores avaliaram o desempenho e o perfil lipídico da carne de ovinos alimentados com grão de soja extrusado, semente de girassol e misturas de ambos em diferentes proporções, a saber: $0 \%$ de inclusão; $15 \%$ de grão de soja; $7,5 \%$ de grão de soja; $10 \%$ de semente de girassol; $20 \%$ de semente de girassol; 7,5 \% grão de soja $+10 \%$ girassol. As sementes de girassol foram quebradas grosseiramente apenas para permitir a peletização. Não foram observadas diferenças entre os tratamentos quanto ao desempenho e às características de carcaça. Os teores de C18:0 e de ácidos graxos saturados totais foram menores para os animais que consumiram a dieta $20 \%$ de girassol e $7,5 \%+10 \%$, enquanto C18:2, C18:3 e ácidos poli-insaturados totais foram maiores nos mesmos grupos, sendo o C18:2 sempre incrementado em dietas que continham pelo menos $10 \%$ de semente oleaginosa. A equipe afirmou que a adição de sementes de girassol parcialmente quebradas pareceu ser a melhor estratégia para que mais ácidos insaturados escapassem da biohidrogenação e que os altos teores de C18:3 nos animais que consumiram dietas ricas em sementes de girassol poderiam estar relacionados ao alto teor de C18:2 dessas dietas.

Ponnampalam et al. (2002b) suplementaram ovinos com tremoço, farinha de peixe, cevada, cevada + tremoço e cevada + farinha de peixe. Comparando com o grupo controle, foram observados $27 \%$ e $16 \%$ de incremento em $\omega-6$ nos músculos para os tratamentos ceva$\mathrm{da}+$ tremoço e tremoço, respectivamente, fatos associados com o incremento no consumo de $\omega-6$ dietético. Ainda, os autores destacaram acréscimos de $53 \%$ (farinha de peixe) e $52 \%$ (cevada + farinha de peixe) nos teores de $\omega-3$ (cadeia longa) na carne, os quais se justificaram pelo incremento dietético de $\omega-3$ provido pelos suplementos. Contudo, uma informação foi merecidamente enfatizada pelos autores: a dieta cevada + farinha de peixe forneceu $50 \%$ a menos de $\omega$-3 quando comparada a farinha de peixe sozinha, o que sugere que pode haver

Tabela II. Classes de ácidos graxos (mg/100g de carne fresca) e relações do músculo longissimus (fosfolipídios e lipídios neutros combinados) em ovinos consumindo dietas com diferentes fontes de ácidos graxos. (Fatty acid classes (mg/100g fresh meat) and relationships of the longissimus muscle (phospholipids and neutral lipids combined) in ovine animals consuming diets with different sources of fatty acids).

\begin{tabular}{|c|c|c|c|c|c|}
\hline Item & $\mathrm{LO}^{1}$ & $\mathrm{FO}^{2}$ & $\mathrm{PLS}^{3}$ & FO/Algae & PLS/Algae \\
\hline $\mathrm{SFA}^{4}$ & 1.388 & 1.528 & 1.446 & 1.490 & 1.516 \\
\hline MUFA $^{5}$ & 1.186 & 1.256 & 1.231 & 1.168 & 1.227 \\
\hline PUFA $^{6}$ & $333^{\mathrm{hi}}$ & $275^{\mathrm{h}}$ & $784^{i}$ & $427^{i}$ & $686^{\mathrm{j}}$ \\
\hline n-6 PUFA ${ }^{7}$ & $191^{\mathrm{h}}$ & $143^{\text {h }}$ & $595^{j}$ & $174^{\mathrm{h}}$ & $428^{i}$ \\
\hline n-3 PUFA ${ }^{8}$ & $142^{\mathrm{h}}$ & $132^{\mathrm{h}}$ & $189^{i}$ & 254 & $257^{j}$ \\
\hline$P: S^{9}$ & $0,26^{\mathrm{hi}}$ & $0,19^{h}$ & $0,57^{\mathrm{k}}$ & $0,30^{i}$ & $0,46^{i}$ \\
\hline$n-6 / n-3$ & $1,37^{j}$ & $1,10^{i}$ & $3,15^{\prime}$ & $0,68^{\mathrm{h}}$ & $1,70^{\mathrm{k}}$ \\
\hline
\end{tabular}

${ }^{1} \mathrm{LO}=$ óleo de linhaça; ${ }^{2} \mathrm{FO}=$ óleo de peixe; ${ }^{3} \mathrm{PLS}=$ sementes de linhaça e soja protegidas. Algae= algas marinhas. ${ }^{4} \mathrm{SFA}=$ ácidos graxos saturados $(14: 0+16: 0+18: 0) ;{ }^{5} \mathrm{MUFA}=$ ácidos graxos monoinsaturados $(16: 1 n-9+18: 1 n-9+18: 1 n-7+20: 1 n-9) ;{ }^{6}$ PUFA $=18: 2 n-6+18: 3 n-3+20: 3 n-6+20: 4 n-6+20: 5 n-3+$ $22: 4 n-6+22: 5 n-3+22: 6 n-3 ;{ }^{7} n-6$ PUFA $=18: 2 n-6+20: 3 n-6+20: 4 n-6+22: 4 n-6 ;{ }^{8} n-3$ PUFA $=18: 3 n-3$ $+20: 5 n-3+22: 5 n-3+22: 6 n-3 ;{ }^{9} P: S=$ relação entre ácidos graxos poli-insaturados totais e saturados totais. Fonte: adaptado de Cooper et al. (2004). 
um limite para deposição de $\omega$-3 nos músculos de ovinos. Ponnampalam et al. (2001) afirmaram que a relação entre nível de consumo de ácidos graxos de cadeia longa da série $\omega-3$ e sua subsequente taxa de incorporação no músculo (tanto nos fosfolipídios quanto nos triglicerídios) ainda é muito pouco entendida.

Além das sementes oleaginosas e dos alimentos frequentemente utilizados na nutrição animal, outros ingredientes têm emergido como fonte alternativa de gordura. Cooper et al. (2004) avaliaram a inclusão do óleo de linhaça, óleo de peixe, sementes de linhaça e soja protegidas (encapsuladas em proteína tratada com formaldeído) e extrato de algas marinhas como fontes de lipídios na dieta de ovinos (tabela II). A combinação entre óleo de peixe e algas (50:50) e gordura protegida + algas em proporções iguais também foram avaliadas. Não houve efeito no consumo de matéria seca e no desempenho, mas o perfil lipídico da fração fosfolipídica e dos triglicerídios do músculo foram influenciados pelas dietas. O teor de ácidos graxos poli-insaturados foi 2,5 vezes maior quando a suplementação consistiu em gordura protegida, fosse sozinha ou combinada com o extrato de algas. A suplementação com gordura protegida + algas marinhas produziu uma relação poliinsaturado/saturado mais favorável, em termos nutricionais. Contudo, os tores de EPA e DHA foram baixos na fração fosfolipídica quando os animais foram suplementados com óleo de linhaça ou gordura protegida, em comparação à suplementação com óleo de peixe ou extrato de algas. Os autores concluíram que o suporte dietético de ácidos poli-insaturados $\omega$-3 é necessário se o objetivo é promover o incremento destes ácidos na carne.

Bessa et al. (2005) mostraram que o enriquecimento de CLA na carne pode não estar relacionado apenasao tipo de lipídio utilizado na suplementação, mas também à base da dieta (concentrado ou volumoso). Em condições experimentais, ovinos foram alimentados com quatro dietas diferentes: feno de luzerna, feno de luzerna + óleo de soja, concentrado, concentrado + óleo de soja. Nos tratamentos que continham óleo, a inclusão foi num teor de $10 \%$ da matéria seca. A suplementação com óleo na dieta a base de feno foi mais efetiva em enriquecer a carne com CLA trans-11 e C18:1 trans-11 (que pode ser convertido em CLA trans-11 em humanos). A dieta a base de concentrado suplementada com óleo aumentou o teor de C18:1 trans-10, mas a concentração de CLA foi muito baixa, provando que o efeito da suplementação com óleo de soja foi dependente da dieta base.

O óleo de dendê natural e na forma de sabões de cálcio foi testado como fonte lipídica na alimentação de ovinos por Castro et al. (2005). As dietas variaram de acordo com o nível de óleo de dendê ou sabão de cálcio, a saber: controle; baixo $(2,5 \%)$ e alto $(4,1 \%)$ nível de óleo de dendê; baixo $(3,1 \%)$ e alto $(5,0 \%)$ nível de sabão de cálcio. O perfil da gordura intramuscular não foi afetado pelos tratamentos, com exceção do total de ácidos graxos monoinsaturados, que foi superior para a dieta controle. Por conter maior teor de milho que as outras dietas, a dieta base continha cerca de $40 \%$ a mais de C18:2, o qual pode inibir a biohidrogenação completa, gerando maior quantidade de intermediários insaturados (Beam et al., 2000).

O tratamento com formaldeído é conhecido como o mais eficiente em proteger lipídios da biohidrogenação, permitindo que apenas $13 \%$ da gordura seja metabolizada pelos microorganismos (Gulati et al., 1997). Contudo, por existir uma remota possibilidade de transferência do formaldeído para os produtos de origem animal, seu uso é proibido nos Estados Unidos. Testando outra forma de proteção do lipídio, Lee et al. (2007) avaliaram o efeito da suplementação de ovinos com óleo de girassol em gel protegido através do tratamento com diacetil. O suplemento continha 15,2\% de extrato etéreo, dos quais 71,2\% correspondiam a C18:2 n-6. Os autores relataram que a proteção foi eficiente por causar decréscimo no teor de ácido palmítico e incremento no teor de C18:2 n-6 (5,8\% para $11,7 \%)$ na carne 
dos animais. Concluiu-se que o tratamento do óleo com diacetil protegeu o ácido linoléico da biohidrogenação, favorecendo sua incorporação no tecido muscular.

Ainclusão da semente de linhaça extrusada na dieta de ovinos $(0,3,6$ e $9 \%)$ foi avaliada por Bas et al. (2007). Após o desmame, os animais tiveram acesso à palha de trigo e ao concentrado ad libitum, sendo abatidos ao fim da sétima semana experimental. Não houve efeito da suplementação sobre o desempenho animal e características de carcaça. Os principais efeitos no perfil lipídico da carne foram o incremento no teor de C18:3 n-3 e a redução nos ácidos graxos de cadeia ímpar. Verificou-se maior teor de C20:3 n-3 e C20:5 n-3 e menor teor de C18:3 n-6. Por consequência destes resultados, constatou-se maior valor no total de ácidos graxos poli-insaturados e decréscimo na relação $\omega-6 / \omega-3$ na carne dos animais suplementados com semente de linhaça. Como a oferta de ácido linoleico via dieta foi praticamente a mesma nos quatro tratamentos, não houve variação deste ácido graxo na carne dos animais. Já o ácido oleico, que teve sua oferta dietética aumentada de acordo com os níveis de inclusão da semente, apareceu em menores proporções nos tecidos adiposo e muscular dos animais que consumiram $9 \%$ de semente. Os autores sugeriram que isto pode estar relacionado à menor atividade da $\Delta 9$ dessaturase, que produz ácido oleico a partir do esteárico. Ainda, observou-se que a suplementação com semente de linhaça tendeu a aumentar os tores de ácidos graxos trans, sobretudo o $\mathrm{C} 18: 1$ trans-10, que não traz efeitos benéficos à saúde humana. Este aumento está relacionado à baixa relação volumoso:concentrado. Os autores afirmaram que o consumo de palha de trigo provavelmente foi inferior a $10 \%$. Este resultado não permite inferir que a suplementação com semente de linhaça está correlacionada com maiores teores de gordura trans, é possível que resultados diferentes sejam obtidos em experimentos em que a oferta de concentrado seja limitada.
Kitessa et al. (2009) avaliaram o efeito da suplementação com óleo de linhaça protegido (tratado com formaldeído) durante três, seis e nove semanas sobre o desempenho animal, parâmetros sensoriais e perfil lipídico da carne de ovinos. Os animais do grupo controle consumiram $1,2 \mathrm{~kg} /$ dia de dieta balanceada (feno + concentrado) durante as nove semanas; os animais que receberam o suplemento consumiram $1,080 \mathrm{~kg}$ da dieta $+120 \mathrm{~g} / \mathrm{dia}$ do suplemento (3\% MS). Não foi verificado efeito algum sobre o desempenho animal e características de carcaça, bem como sobre os parâmetros sensoriais da carne, com exceção do atributo sabor forte, em que a menor e maior nota foram atribuídas aos tratamentos três e nove semanas, respectivamente. Já para o perfil lipídico da carne, verificou-se aumento na concentração de ácidos graxos insaturados totais, ácido linoléico, linolênico e nos ácidos graxos poli-insaturados de cadeia longa da série $\omega$-3 Para estes últimos, o incremento só ocorreu após seis ou nove semanas de suplementação, enquanto a resposta para os ácidos linoléico e linolênico ocorreu após três semanas de suplementação. A suplementação não surtiu efeito sobre os teores de ácido araquidônico (C20:4 n-6). Os resultados confirmaram a eficiência de enriquecimento de C18:3 n-3 na carne através do enriquecimento dietético do mesmo (o óleo de linhaça é rico C18:3 n-3), contudo, o enriquecimento de ácidos de cadeia longa da série $\omega-3$ foi menos eficiente, além de requerer um maior período de suplementação. Os autores reportaram que isto ocorre em quase todos os casos de suplementação com óleos vegetais, mas não se sabe se existe alguma deficiência dos ovinos relacionada ao sistema enzimático responsável pela conversão de $\mathrm{C} 18: 3 \mathrm{n}-3 \mathrm{em}$ EPA, DPA e DHA. É importante salientar que longos períodos de suplementação podem não ser economicamente viáveis.

Em relação ao efeito do tempo de suplementação sobre o enriquecimento de CLA na carne de ovinos, mais especificamente o ácido rumênico, Bessa et al. (2008) verificaram que curtos períodos de suplementação (14 ou 28 


\section{DIFERENTES FONTES DE GORDURA SOBRE A MODULAÇÃO DO PERFIL DE ÁCIDOS}

dias) com óleo de soja não protegido são muito eficientes em incrementar a concentração de CLA na carne. Contudo, corroborando com Kitessa et al. (2009), a suplementação no curto período não foi eficiente em incorporarácidos $\omega-3$ e $\omega-6$ de cadeia longa à carne, mas as concentrações de ácido linoleico e linolênico aumentaram com a suplementação. Adicionalmente, os pesquisadores avaliaram a influência de dietas prévias à suplementação - ricas em concentrado ou ricas em volumoso - sobre a deposição de ácido rumênico. Verificou-se uma tendência à menor deposição deste CLA quando as d ietas iniciais foram ricas em concentrado, comportamento previamente observado por Bessa et al. (2005). Este fato pode estar relacionado à influência do $\mathrm{pH}$ ruminal nos processos de lipólise e biohidrogenação reportados por Beam et al. (2000): alto teor de concentrado tende a diminuir o $\mathrm{pH}$ do rúmen, que deprecia as taxas de biohidrogenção. Nesta circunstância, podem surgir vias alternativas, as quais produzem $\mathrm{C} 18: 1$ trans-10 a partir do C18:2 n-6 (fornecido via óleo de soja), ao invés de produzir C18:1 trans-11 (Griinari e Bauman, 1999), que é o principal precursor do ácido rumênico nos tecidos (via $\Delta 9$ dessaturase).

Manso et al. (2009) avaliaram o efeito da suplementação de ovinos com $4 \%$ de óleo de dendê hidrogenado ou óleo de semente de girassol. $\mathrm{O}$ desempenho animal não foi influenciado pela substituição, bem como as características de carcaça e os parâmetros físico-químicos da carne. Quanto ao perfil lipídico da carne, o óleo de dendê hidrogenado não causou mudanças quando comparado ao controle, enquanto a suplementação com óleo de semente de girassol provocou decréscimo nos teores de ácido palmítico, de C18:1 cis-

Tabela III. Efeito da substituição do óleo de girassol por óleo de linhaça no perfil de ácidos graxos do músculo longissimus (g/100g ácido graxo) de ovinos Merino Branco. (Effect of replacement of sunflower oil by linseed oil on fatty acid profile of the longissimus muscle $(\mathrm{g} / 100 \mathrm{~g}$ fatty acid) of White Merino sheep).

\begin{tabular}{lccccc}
\hline \multirow{2}{*}{ Ácido graxo } & \multicolumn{3}{l}{ Nível de substituição do óleo de girassol por óleo de linhaça (\%) } & \multirow{2}{*}{$\mathrm{p}$} \\
\cline { 2 - 4 } & 0 & 33,3 & 66,6 & 100 & \\
\hline C14:0 & 1,55 & 1,72 & 1,78 & 1,70 & $>0,05$ \\
C16:0 & 18,10 & 19,20 & 18,60 & 18,20 & $>0,05$ \\
C18:0 & 14,80 & 14,80 & 14,40 & 14,30 & $>0,05$ \\
C18:1 t11 & 5,90 & 5,50 & 5,18 & 4,85 & $<0,05$ \\
C18:1 c9 & 26,30 & 28,00 & 26,50 & 26,90 & $>0,05$ \\
C18:2 n-6 & 9,36 & 7,52 & 6,74 & 5,09 & $<0,001$ \\
C18:3 n-3 & 0,93 & 1,57 & 2,62 & 3,05 & $<0,001$ \\
CLA & 2,13 & 2,06 & 1,84 & 1,56 & $<0,001$ \\
& & & & & \\
SFA & 36,00 & 37,20 & 36,20 & 35,60 & $>0,05$ \\
MUFA & 40,60 & 41,60 & 39,20 & 39,89 & $>0,05$ \\
PUFA & 26,90 & 24,50 & 25,90 & 23,60 & $<0,05$ \\
P:S & 0,30 & 0,25 & 0,27 & 0,24 & $>0,05$ \\
n-6 PUFA & 12,30 & 9,82 & 8,98 & 6,96 & $<0,001$ \\
n-6 LC-PUFA & 2,94 & 2,30 & 2,25 & 1,87 & $<0,001$ \\
n-3 PUFA & 1,74 & 2,61 & 4,01 & 4,38 & $<0,001$ \\
n-3 LC-PUFA & 0,81 & 1,04 & 1,39 & 1,33 & $<0,001$ \\
n-6:n-3 & 7,04 & 3,78 & 2,26 & 1,60 & $<0,001$ \\
\hline SFA a a cids & &
\end{tabular}

SFA= ácidos graxos saturados; MUFA= ácidos graxos monoinsaturados; PUFA= ácidos graxos poliinsaturados; LC-PUFA: ácidos graxos poli-insaturados de cadeia longa. Fonte: adaptado de Jerónimo et al. (2009). 
11, C18:3 e acréscimo no teor de C18:1 trans (sem maiores especificações).

Alguns autores já relataram que suplementar ruminantes com óleos ricos em C18:2 n-6 e C18:3 n-3 tende a enriquecer a carne de tais animais com CLA, sobretudo o C18:2 cis-9, trans-11. O óleo de linhaça é rico em C18:3 $\mathrm{n}-3$, enquanto o de girassol é rico em C18:2 n-6. Neste sentido, Jerónimo et al. (2009) alimentaram ovinos com níveis crescentes de óleo de linhaça $(0,33,66$ e $100 \%)$ em substituição ao óleo de girassol objetivando determinar que mistura seria mais eficiente em modificar favoravelmente o perfil lipídico da carne. Independente do percentual de substituição, os animais foram suplementados com $6 \%$ de óleo vegetal. Observou-se efeito linear crescente de acordo com os níveis de substituição para o ganho médio diário, peso corporal ao abate, peso de carcaça quente e percentual de gordura intermuscular. Os principais efeitos da substituição sobre o perfil lipídico da carne constam na tabela III. Os animais que consumiram $100 \%$ de óleo de girassol (grupo controle) apresentaram $46 \%$ mais C18:2 n-6 e $40 \%$ mais n-6 PUFA do que os animais que consumiram $100 \%$ de óleo de linhaça, contudo, estes últimos apresenta- ram proporcionalmente mais n-6 PUFA-LC $(1,87 / 6,96)$ que os primeiros $(2,94 / 12,3)$. É fato que a suplementação com óleo de girassol promove maior deposição de CLAe ácidos da série $\omega-6$, enquanto o óleo de linhaça promove maior deposição de ácidos $\omega$-3, porém, a mistura de ambos parece ser uma alternativa válida para produzir carne enriquecida com CLA e ácidos graxos $\omega-3$.

Comparando os resultados de Jerónimo et al. (2009) e Cooper et al., (2004) podese inferir que a suplementação com óleo de peixe pareceu mais eficiente em incrementar os teores de ácidos graxos de cadeia longa da série $\omega-3$, apesar da influência negativa da suplementação com o óleo de peixe sobre a vida de prateleira da carne e alguns aspectos sensoriais (Nute et al., 2007). Mas vale aqui ressaltar que o enriquecimento da carne de ruminantes com ácidos poli-insaturados de cadeia longa ainda é um tema complexo, uma vez que estes ácidos encontram-se muito mais concentrados na membrana fosfolipídica do que nos lipídios neutros e os fosfolipídios da membrana são menos influenciados pela dieta (Wood et al., 2003; Jerónimo et al. 2009). Wood et al. (2008) sugeriram que a capacidade de incorporação de ácidos graxos

Tabela IV. Concentração de ácidos graxos (ésteres metílicos, g/100g) da gordura intramuscular de ovelhas alimentadas com diferentes sementes oleaginosas. (Concentration of fatty acids (methyl esters, $\mathrm{g} / 100 \mathrm{~g}$ ) of intramuscular fat of sheep fed with different oilseeds).

\begin{tabular}{lccccc}
\hline \multirow{2}{*}{ Àcido graxo } & \multicolumn{3}{c}{ Tratamentos } \\
\cline { 2 - 6 } & Controle & Linhaça & Colza & Cártamo & Girassol \\
\hline C16:0 & $28,70^{\mathrm{a}}$ & $27,65^{\mathrm{ab}}$ & $28,87^{\mathrm{a}}$ & $26,27^{\mathrm{b}}$ & $27,76^{\mathrm{ab}}$ \\
C18:0 & $17,13^{\mathrm{ab}}$ & $17,38^{\mathrm{ab}}$ & $17,69^{\mathrm{ab}}$ & $14,91^{\mathrm{b}}$ & $18,51^{\mathrm{a}}$ \\
C18:1 cis-9 n-9 & 31,42 & 33,59 & 32,34 & 34,11 & 34,79 \\
C18:1 trans-11 n-7 & $2,95^{\mathrm{ab}}$ & $3,05^{\mathrm{ab}}$ & $2,46^{\mathrm{b}}$ & $4,69^{\mathrm{a}}$ & $2,22^{\mathrm{b}}$ \\
C18:2 n-6 & $1,77^{\mathrm{b}}$ & 1,86 & 1,57 & 1,75 & 1,80 \\
C18:3 n-3 & $0,86^{\mathrm{a}}$ & $0,85^{\mathrm{ab}}$ & $0,62^{\mathrm{bc}}$ & $0,66^{\mathrm{abc}}$ & $0,52^{\mathrm{c}}$ \\
C18:2 cis-9, trans-11 (CLA) & $0,65^{\mathrm{b}}$ & $0,56^{\mathrm{b}}$ & $0,58^{\mathrm{b}}$ & $0,89^{\mathrm{a}}$ & $0,84^{\mathrm{a}}$ \\
n-6/n-3 & 2,30 & 2,51 & 3,79 & 2,92 & 4,02 \\
PUFA & 3,80 & 3,79 & 3,17 & 3,45 & 3,50 \\
SFA & $59,46^{\mathrm{a}}$ & $57,44^{\mathrm{ab}}$ & $59,95^{\mathrm{a}}$ & $53,03^{\mathrm{b}}$ & $57,71^{\mathrm{a}}$ \\
PUFA/SFA & 0,06 & 0,07 & 0,05 & 0,06 & 0,06 \\
\hline
\end{tabular}

a,b,c Médias seguidas de letras diferentes diferem estatisticamente $(p<0,05)$; SFA= ácidos graxos saturados; PUFA= ácidos graxos poli-insaturados. Fonte: adaptado de Peng et al. (2010). 
Tabela $\boldsymbol{V}$. Composição de ácidos graxos da gordura intramuscular (mg/100g de músculo) no músculo longissimus lumborum de caprinos de acordo com os tratamentos dietéticos. (Fatty acid composition of intramuscular fat (muscle $\mathrm{mg} / 100 \mathrm{~g}$ ) on muscle longissimus lumborum of goats according to dietary treatments).

\begin{tabular}{lccc}
\hline \multirow{2}{*}{ Ácido graxo } & \multicolumn{3}{c}{ Dietas } \\
\cline { 2 - 4 } & Óleo de dendê & Óleo de soja & Óleo de peixe \\
\hline C14:0 & 58,1 & 59,8 & 62,3 \\
C16:0 & $698^{\mathrm{a}}$ & $667^{\mathrm{b}}$ & $691^{\mathrm{a}}$ \\
C16:1 & 138 & 140 & 142 \\
C18:0 & $413^{\mathrm{a}}$ & $380^{\mathrm{b}}$ & $415^{\mathrm{a}}$ \\
C18:1 & 1373 & 1389 & 1398 \\
C18:2 & $119^{\mathrm{b}}$ & $171^{\mathrm{a}}$ & $115^{\mathrm{b}}$ \\
C18:3 & $13,1^{\mathrm{b}}$ & $22,9^{\mathrm{a}}$ & $15,0^{\mathrm{b}}$ \\
C20:4 n-6 & $20,6^{\mathrm{a}}$ & $19,8^{\mathrm{a}}$ & $10,1^{\mathrm{b}}$ \\
C20:5 n-3 & $5,7^{\mathrm{b}}$ & $6,3^{\mathrm{b}}$ & $19,4^{\mathrm{a}}$ \\
C22:6 n-3 & $5,0^{\mathrm{b}}$ & $6,2^{\mathrm{b}}$ & $18,3^{\mathrm{a}}$ \\
C20:5 n-3+C22:6 n-3 & $10,7^{\mathrm{b}}$ & $12,6^{\mathrm{b}}$ & $37,8^{\mathrm{a}}$ \\
SFA & $1169^{\mathrm{a}}$ & $1107^{\mathrm{b}}$ & $1168^{\mathrm{a}}$ \\
MUFA & 1511,2 & 1529,1 & 1540 \\
PUFA & $164^{\mathrm{b}}$ & $226^{\mathrm{a}}$ & $178^{\mathrm{b}}$ \\
P/S & $0,14^{\mathrm{b}}$ & $0,20^{\mathrm{a}}$ & $0,15^{\mathrm{b}}$ \\
n-6 & $139^{\mathrm{b}}$ & $191^{\mathrm{a}}$ & $126^{\mathrm{b}}$ \\
n-3 & $23,9^{\mathrm{c}}$ & $35,5^{\mathrm{b}}$ & $52,8^{\mathrm{a}}$ \\
n-6/n-3 & $5,8^{\mathrm{a}}$ & $5,4^{\mathrm{a}}$ & $2,4^{\mathrm{b}}$ \\
\hline
\end{tabular}

a,b,c Médias seguidas de letras diferentes diferem estatisticamente $(p<0,05)$ pelo teste de Tuckey; SFA= ácidos graxos saturados; MUFA= ácidos graxos monoinsaturados; $P U F A=$ ácidos graxos poli-insaturados; P/S= poli-insaturados / saturados. Fonte: adaptado de Najafi et al. (2012).

poli-insaturados na membrana fosfolipídica é limitada.

As diferentes composições lipídicas das sementes oleaginosas levaram Peng et al., (2010) a avaliar o efeito da suplementação de ovelhas com sementes de colza (rica em ácido oleico), sementes de girassol e cártamo (ricas em ácido linoleico) e sementes de linhaça (rica em ácido linolênico). As sementes foram fornecidas na forma de farelo, em uma quantidade diária necessária para prover $36 \mathrm{~g}$ de óleo, com exceção do tratamento cártamo, em que a quantidade de semente fornecida foi capaz de fornecer $55 \mathrm{~g}$ de óleo. Os animais que receberam a suplementação com as diferentes sementes não diferiram daqueles que receberam a dieta controle quanto ao peso de carcaça e composição química do longissimus lumborum. O ganho médio diário foi menor para os animais do grupo controle (112g/dia).
Para os animais suplementados, o menor ganho médio diário foi observado para aqueles que consumiram semente de cártamo e o maior para o grupo que recebeu semente de colza. O perfil lipídico da gordura intermuscular foi influenciado pelas diferentes suplementações (tabela IV). As sementes de cártamo e girassol foram mais eficientes em enriquecer a gordura intramuscular com CLA, haja vista suas riquezas em ácido linolênico.

Najafi et al. (2012) alimentaram caprinos em condições experimentais com dietas isoprotéicas e isoenergéticas, formuladas com os mesmos ingredientes, mas suplementadas com diferentes fontes lipídicas: óleo de dendê, óleo de soja e óleo de peixe. Não foram verificadas diferenças entre os tratamentos em relação ao desempenho animal, características de carcaça, rendimento de cortes cárneos comerciais e parâmetros físico-químicos da 
carne. O perfil lipídico da carne caprina foi diretamente influenciado pelos tratamentos (tabela V) e, de certa forma, retrataram a composição das diferentes fontes lipídicas: a suplementação com óleo de dendê favoreceu maior concentração de C16:0 na carne; o óleo de soja, rico em C18:2, proporcionou carnes $30 \%$ mais ricas em ácido linoléico quando comparadas aos outros tratamentos; o óleo de peixe enriqueceu a carne dos animais com ácidos graxos poli-insaturados de cadeia longa da série $\omega-3$. É possível que a menor concentração de C16:0 e C18:0 na carne de animais suplementados com óleo de soja estejam relacionados à diminuição da síntese de ácidos graxos pelos micro-organismos, que ocorre sempre que a oferta exógena é aumentada (Palmquist e Mattos, 2006). As concentrações de ácido araquidônico (C20:4 n-6) na carne dos animais que foram suplementados com óleos vegetais evidenciam a importância dos processos de elongação e dessaturação dos produtos intermediários da biohidrogenação que ocorrem em nível de rúmen, uma vez que as fontes lipídicas de origem vegetal não contêm este ácido graxo em suas composições. A recomendação nutricional quanto a relação poli-insaturado:saturado é de no mínimo 0,45 (Lima et al., 2000), e desse modo, a suplementação com óleo de soja favoreceu a produção de uma carne mais saudável. Contudo, as recomendações para ingestão de ácidos graxos $\omega$-3 são de igual ou maior importância que a relação $\mathrm{P}: \mathrm{S}$, valorizando nutricionalmente a carne dos animais alimentados com óleo de peixe. A concentração de ácidos poli-insaturados de cadeia longa na carne dos animais alimentados com óleo de peixe sugere que tais ácidos são mais resistentes à biohidrogenação ruminal.

Recentemente, Qwele et al. (2013) conduziram um ensaio em que caprinos foram alimentados com feno de gramínea (rico em ácidos graxos saturados), folhas desidratadas de Moringa oleífera (rica em C18:1) e torta de semente de girassol (rica em C18:2). O feno foi fornecido ad libitum enquanto a torta de girassol e as folhas de moringa foram fornecidas em nas quantidades de $170 \mathrm{~g} / \mathrm{dia}$ e $200 \mathrm{~g} /$ dia, respectivamente. Pelo diferente teor lipídico dos ingredientes utilizados, as dietas apresentaram diferentes teores de extrato etéreo: $0,95 \%$ (feno); $6,55 \%$ (torta de girassol); $1,76 \%$ (folhas de moringa). A carne dos animais alimentados com feno apresentou menores teores de proteína, gordura, colesterol e cinzas, bem como maior teor de umidade. Quanto ao perfil dos ácidos graxos da carne, os animais que consumiram feno apresentaram maiores concentrações de ácidos graxos $\omega$-3, $\omega-6$ e CLA, além de maiores teores de ácidos graxos saturados. Quando alimentados com moringa ou torta de girassol, os caprinos produziram carnes com teores similares de ácidos graxos saturados e monoinsaturados, contudo, a suplementação com torta de girassol levou a um menor teor de ácidos poli-insaturados.

Karami et al. (2013) compraram o efeito da suplementação de caprinos com óleo de canola ou dendê (3\% da matéria seca) sobre o perfil de ácidos graxos do músculo longissimus lumborum. Os tratamentos não tiveram efeito sobre o desempenho animal, características de carcaça, peso e composição tecidual dos cortes cárneos. No perfil lipídico da carne, a principal diferença foi quanto ao teor de ácidos graxos poli-insaturados, sobretudo do C18:3, que foi maior na carne dos animais suplementados com óleo de canola.

Visando baratear os custos de produção e contribuir com o meio-ambiente, alguns subprodutos agroindustriais têm sido utilizados na alimentação animal, contudo, os efeitos da inclusão de tais ingredientes precisam ser avaliados. Neste sentido, Luciano et al. (2013) forneceram torta de oliva a ovinos e compararam o efeito desta inclusão com a suplementação com linhaça, um ingrediente utilizado com maior frequência. Os pesquisadores testaram quatro dietas experimentais: controle; $20 \%$ de semente de linhaça; $35 \%$ de torta de oliva; mistura de $10 \%$ de linhaça com $17 \%$ de torta de oliva. O teor médio de extrato etéreo das dietas foi $10 \%$, exceção seja feita para a dieta controle, que continha apenas 
2,3 \% de gordura. Não houve influência sobre o percentual de gordura intramuscular, mas em relação ao perfil lipídico, observou-se que a linhaça foi mais eficiente em incorporarácidos graxos poli-insaturados à carne, enquanto os menores teores foram verificados quando a suplementação consistiu em torta de oliva. Todavia, vale destacar que a suplementação com a mistura dos ingredientes não apresentou diferença estatística quando comparada à dieta que continha apenas linhaça, indicando uma alternativa para melhorar o perfil lipídico da carne a custos reduzidos.

Além de o perfil lipídico da carne de pequenos ruminantes ser modificado através da manipulação da dieta, existe a possibilidade de tal modificação ser feita indiretamente, leia-se: através da modificação da composição do leite materno. Ruminantes exclusivamente lactantes são considerados monogástricos funcionais devido ao não funcionamento do rúmen, esta condição protege os ácidos graxos poli-insaturados da dieta do processo de biohidrogenação, favorecendo a deposição de ácidos graxos poli-insaturados nos depósitos adiposos destes animais (Lanza et $a l ., 2006)$. No caso de animais lactantes não exclusivos, esta possibilidade ainda é real devido à formação da goteira esofágica no momento da mamada, desviando o leite do rúmen-retículo e conduzindo-o diretamente para o abomaso. É fato que a composição do leite de cabras e ovelhas sofre influência direta da dieta, sobretudo quando fêmeas em lactação são suplementadas com lipídios (Goulas et al., 2003). Joy et al. (2012) relataram que o leite de ovelhas teve a composição alterada mediante a alimentação das mesmas com feno ou forragem verde, fosse no período pré-parto ou no pós-parto. Kennelly (1996) citou que fêmeas lactantes alimentadas com suplementos lipídicos protegidos contendo óleo de linhaça e de cártamo apresentaram incrementos da ordem de $30 \%$ e $20 \%$ de C18:2 e C18:3, respectivamente. Diante disto, muitos pesquisadores têm investigado o efeito da suplementação de ovelhas lactantes sob o perfil lipídico dos depósitos adiposos das crias.

Lanza et al. (2006) compararam o efeito da amamentação natural de ovinos e do fornecimento de sucedâneo sobre o perfil lipídico da carne dos cordeiros e verificaram que, dos 28 ácidos graxos identificados, 24 foram afetados pelos diferentes tipos de alimentos. O substituto do leite promoveu maiores teores de ácidos graxos poli-insaturados na carne, com destaque para os da classe $\omega-6$.

Nudda et al. (2008) dividiram cabras paridas em dois grupos: suplementadas com semente de linhaça extrusada; suplementadas com caroço de algodão. A suplementação em ambos os grupos foi suficiente para fornecer $32 \mathrm{~g}$ de ácidos graxos por dia. As cabras foram suplementadas durante duas semanas $\left(4^{\mathrm{a}}\right.$ e $5^{\mathrm{a}}$ semana pós-parto) e os cabritos continuaram mamando durante este período, sendo abatidos uma semana após o término da suplementação. As crias das cabras suplementadas com linhaça apresentaram carnes com maiores teores de C18:1 trans-11, C18:3 n-3, C20:5 n-3 (EPA) e ácidos graxos poli-insaturados $\omega-3$. Já Lurueña-Martínez et al. (2010) forneceram $4 \%$ de sabão de cálcio de óleo de dendê a ovelhas lactantes e não verificaram efeitos benéficos na alteração do perfil lipídico da carne das crias, provavelmente devido à composição do óleo de dendê, que é rico em gordura saturada.

\section{CONSIDERAÇÕES FINAIS}

Os processos metabólicos aos quais os lipídios dietéticos são submetidos no interior do rúmen - sobretudo a lipólise e a biohidrogenação - são majoritariamente responsáveis pelo perfil lipídico característico da carne de pequenos ruminantes, que apesar de ser fonte primordial de CLA, não satisfaz o consumidor moderno devido aos altos teores de ácidos graxos saturados, correlacionando a carne à ocorrência de doenças cardiovasculares. O mercado atual exige alimentos saudáveis, ricos em ácidos graxos poli-insaturados e complexos bioativos, exige, portanto, a modificação do perfil de ácidos graxos da carne 
destes animais, que não é simples dada a complexidade do ecossistema microbiano ruminal.

São os alimentos e a alimentação que exercem maior influência sobre a composição lipídica da carne de caprinos e ovinos, dessa forma, a manipulação dietética parece ser a maneira mais eficiente de alterar o perfil lipídico da carne. A literatura sugere que suplementação com lipídios ricos em ácidos graxos poli-insaturados não muda o perfil lipídico padrão da carne-maiores percentuais dos ácidos oléico, palmítico e esteárico-mas é efetiva em diminuir os ácidos graxos saturados e enriquecê-la com ácidos poli-insaturados benéficos à saúde humana.

Os trabalhos revisados não reportaram efeitos negativos da suplementação lipídica ao desempenho animal. Fatores como relação volumoso : concentrado, fonte lipídica usada na suplementação, proteção da gordura e tempo de suplementação têm influência significativa sobre o efeito da inclusão de lipídios na alimentação de pequenos ruminantes. Há evidências que caprinos e ovinos respondem à suplementação lipídica de maneira similar. A inclusão de lipídios na dieta de fêmeas lactantes também tem sido vista como alternativa para modificar a gordura da carne de cordeiros e cabritos.

De uma maneira geral, as sementes oleaginosas e seus respectivos óleos têm se mostrado eficientes em incrementar os teores de ácidos graxos poli-insaturados - sobretudo os da classe $\omega-6$ - na carne de caprinos e ovinos, sendo estes efeitos variáveis de acordo com

\section{BIBLIOGRAFIA}

Abu-Ghazaleh, A.A.; Schingoethe, D.J. and Hippen, A.R. 2001. Conjugated linoleic acid and other beneficial fatty acids in milk fatty from cows fed soybean meal, fish meal, or both. J Dairy Sci, 84:1845-1850.

Aferri, G.; Leme, P.R.; Silva, S.L.; Putrino, S.M. e Pereira,A.S.C. 2005. Desempenho e características de carcaça de novilhos alimentados com dietas contendo diferentes fontes de lipídios. Rev Bras as espécies vegetais e potencializados quando são fornecidos na forma protegida. Já o óleo de peixe e o extrato de algas marinhas são fontes eficazes para maior deposição de ácidos graxos poli-insaturados de cadeia muito longa na carne. Quanto ao incremento no teor de CLA ainda se sabe pouco, mas parece depender da inibição parcial da biohidrogenação, sendo obtidas melhores concentrações quando a suplementação é feita com óleos de origem vegetal. Ainda, é possível que os efeitos da suplementação sobre os teores de CLA estejam associados ao fornecimento, ou não, de forragem.

Muito embora as pesquisas tenham reportado resultados satisfatórios sobre a modificação do perfil lipídico da carne de caprinos e ovinos, alguns passos são limitados pela própria natureza do animal - como a necessidade da ocorrência da biohidrogenação e a limitação da incorporação de ácidos graxos poli-insaturados na membrana fosfolipídica - e a modulação desta natureza tende a ser mais estável e, portanto, menos passível de modulação.

A manipulação do perfil lipídico da carne de ruminantes pode ser considerada uma novidade na ciência animal e ainda há muita coisa a ser esclarecida, dessa forma são necessárias mais pesquisas que investiguem de modo mais profundo como a dieta, e mais precisamente os lipídios, modulam o processos que ocorrem em nível de rúmen e modificam o perfil lipídico da carne de caprinos e ovinos.

Zootecn, 34: 1651-1658.

Anjo, D.F.C. 2004. Alimentos funcionais em angiologia e cirurgia vascular. J Vas Bras, 3:145-154.

Aurousseau, B.; Bauchart, D.; Calichon, E.; Micol, D. and Priolo, A. 2004. Effect of grass or concentrate feeding systems and rate of growth on triglyceride and phospholipid and their fatty acids in the M. longissimus thoracis of lambs. Meat Sci, 66: 531-541.

Balieiro Neto, G. e Melloti, L. 2007. Efeitos de níveis 


\section{DIFERENTES FONTES DE GORDURA SOBRE A MODULAÇÃO DO PERFIL DE ÁCIDOS}

de sebo sobre a degradabilidade in situ do farelo de soja e do feno de tifton \{Cynodon dactylon (L.) pers.\} em vacas secas. Braz J Vet Res Anim Sci, 44: 243-253.

Banskalieva, V.; Sahlu, T. and Goetsch, A.L. 2000. Fatty acid composition of goat muscles and fat depots: a review. Small Rum Resear, 37: 255-268.

Bas, P.; Berthelot, V.; Pottier, E. and Normand, J. 2007. Effect of level of linseed on fatty acid composition of muscles and adipose tissues of lambs with emphasis on trans fatty acids. Meat Sci, 77: 678-688.

Beam, T.M.; Jenkins, T.C.; Moate, P.J.; Kohn, R.A.; and Palmquist, D.L. 2000. Effects of amount and source of fat on the rates of lipolysis and biohydrogenation of fatty acids in ruminal contents. $J$ Dairy Sci, 83: 2564-2573.

Bessa, R.J.B.; Lourenço, M.; Portugal, P.V. and Santos-Silva, J. 2008. Effects of previous diet and duration of soybean oil supplementation on light lambs carcass composition, meat quality and fatty acid composition. Meat Sci, 80: 1100-1105.

Bessa, R.J.B.; Portugal, P.V.; Mendes, I.A.; SantosSilva, J. 2005. Effect of lipid supplementation on growth performance, carcass and meat quality and fatty acid composition of intramuscular lipids of lambs fed dehydrated lucerne or concentrate. Livestock Prod Sci, 96: 185-194.

Bessa R.J.B.; Santos-Silva J.; Ribeiro J.M.R. and Portugal, A.V. 2000. Reticulo-rumen biohydrogenation and the enrichment of ruminant edible products with linoleic acid conjugated isomers. Livestock Prod Sci, 63: 201-211.

Blankson H.; Stakkestad, J.A.; Fagertun, H.; Thom, E.; Wadstein, J. and Gudmundsen, O. 2000. Conjugated linoleic acid reduces body fat mass in overweight and obese humans. J Nutrit, 130: 2943-2948.

Bonagurio, S.; Pérez, J.R.O.; Garcia, I.F.F.; Santos, C.L. e Lima, A.L. 2004. Composição centesimal da carne de cordeiros Santa Inês puros e de seus mestiços com Texel abatidos com diferentes pesos. Rev Bras Zootecn, 33: 2387-2393.

Brickner, A.E.; Pires, J.A.A.; Gressley, T.F. and Grummer, R.R. 2009. Effects of abomasal lipid infusion on liver triglyceride accumulation and adipose lipolysis during fatty liver induction in dairy cows. J Dairy Sci, 92: 4954-4961.

Buccioni, A.; Decandia, M.; Minieri, S.; Molle, G. and Cabiddu, A. 2012. Lipid metabolism in the rumen:
New insights on lipolysis and biohydrogenation with an emphasis on the role of endogenous plant factors. Anim Feed Sci Technol, 174: 1-25.

Castro, T.; Manso, T.; Mantecón, A.R.; Guirão, J. and Jimeno, V. 2005. Fatty acid composition and carcass characteristics of growing lambs fed diets containing palm oil supplements. Meat Sci, 69: 757-764.

Cenkvàri, É.; Fekete, S.; Feble, H.; Veresegyházi, T. and Andrásofszky, E. 2005. Investigation on the effects of Ca-soaps of oil linseed on rumen fermentation in sheep on milk composition of goats. J Anim Physiol Anim Nutr, 89: 172-178.

Champe, P.C. and Harvey, R.A. 1997. Bioquímica llustrada. $2^{a}$ ed. Artes Médicas. Porto Alegre. $446 \mathrm{pp}$.

Chilliard, Y. 1993. Dietary fat and adipose tissue metabolism in ruminants, pigs, and rodents: $A$ review. J Dairy Sci, 76: 3897-3931.

Chow, T.T.; Fievez, V.; Moloney, A.P.; Raes, K.; Demeyer, D. and Smet, S. De. 2004. Effect of fish oil on in vitro rumen lipolysis, apparent biohydrogenation of linoleic and linolenic acid and accumulation of biohydrogenation intermediates. Anim Feed Sci Technol, 117: 1-12.

Church, C.D. 1993. Em rumiante: fisiología digestiva y nutrición. $1^{\text {a }}$ ed. Acribia. Zaragoza. 641 pp.

Colmenero, F.J.; Carballo, J. and Cofrades, S. 2001. Healthier meat and meat products: their role as functional foods. Meat Sci, 59: 5-13.

Cooper, S.L.; Sinclair, L.A.; Wilkinson, R.G.; Hallett, K.G.; Enser, M. and Wood, J.D. 2004. Manipulation of the $n-3$ polyunsaturated fatty acid content of muscle and adipose tissue in lambs. J Animal Sci, 82: 1461-1470.

Demirel, G.; Ozpinar, H.; Nazli, B. and Keser, O. 2006. Fatty acids of lamb meat from two breeds fed different forage: concentrate ratio. Meat Sci, 72: 229-235.

Dias, J.C.; Martins, J.A.M.; Emerick, L.L.; Souza, F.A. e Andrade, V.J. 2009. Efeitos da suplementação lipídica no aumento da eficiência reprodutiva de fêmeas bovinas. Rev Bras Reprod Anim, 33: 95-104.

Elmore, J.S.; Cooper, S.L.; Enser, M.; Mottram, D.S.; Sinclair, L.A.; Wilkinson, R.G. and Wood, J.D. 2005. Dietary manipulation of fatty acid composition in lamb meat and its effect on the volatile aroma compounds of grilled lamb. Meat Sci, 69: 233-242. 


\section{URBANO, FERREIRA, OLIVEIRA, LIMA JÚNIOR E ANDRADE}

Fellner, V.; Sauer, F.D. and Kramer, J.K.G. 1997. Effect of nigericin, monensin, and tetronasin on biohydrogenation in continuous flow-through ruminal fermentors. J Dairy Sci, 78: 1815-1823.

Ferguson, L.R. 2010. Meat and cancer. Meat Sci, 84: 308-313.

Gaili, E.S. and Ali, A.E. 1985. Meat from Sudan desert sheep and goats: part 2-composition of the muscular and fatty tissues. Meat Sci, 13: 229-236.

Gerrard, D.E. and Grant, A.L. 2006. Principles of animal growth and development. Kendall/Hunt Publishing Company. Purdue University. E.U.A. $264 \mathrm{pp}$.

Gerson, T.; John, A. and Sinclair, B.R. 1983. The effects of dietary $\mathrm{N}$ on in vitro rates of lipolysis and fatty acid hydrogenation in rumen digesta from sheep fed diets high in starch. J. Agric Sci, 101: 97-101.

Gerson, T.; King, A.S.D.; Kelly, K.E. and Kelly, W.J. 1988. Influences of particle size and surface area on in vitro rates of gas production, lipolysis of triacylglycerol and hydrogenation of linoleic acid by sheep rumen digesta or Ruminococcus flavefaciens. J Agric Sci, 110: 31-37.

Gibson, R.A. and Makrides, M. 2000. n-3 polyunsaturated fatty acid requirements of term infants. A J Clin Nutrit, 71: 251-255.

Griinari, J.M. and Bauman, D.E. 1999. Biosynthesis of conjugated linoleic acid and its incorporation into meat and milk in ruminants. In: Yurawez, P.; Mossoba, M.M.; Kramer, J.K.G.; Nelson, G.; Pariza, M.W.Advances in conjugated linoleic acid research, $1^{\text {a }}$ ed, American Oil Chemists Society Press. Champaign. 200 pp.

Goulas, C.; Zervas, G. and Papadopoulos, G. 2003. Effect of dietary animal fat and methionine on dairy ewe's milk yield and milk composition. Anim Feed Sci Technol, 105: 43-54.

Gulati, S.K.; Scott, T.W. and Ashes, J.R. 1997. Invitro assessment of fat supplements for ruminants. Anim Feed Sci Technol, 64: 127-132.

Herdmann, A.; Martin, J.; Nuernberg, G.; Wegner, J.; Dannenberger, D. and Nuernberg, K. 2010. How do n-3 fatty acid (short-time restricted vs unrestricted) and n-6 fatty acid enriched diets affect the fatty acid profile in different tissues of German Simmental bulls? Meat Sci, 86: 712-719.

Hoffman, L.C.; Muller, M.; Cloete, S.W.P. and Schmidt, D. 2003. Comparison of six crossbred lamb types: sensory, physical and nutritional meat quality characteristics. Meat Sci, 65: 1265-1274. Ivan, M.; Mir, P.S.; Koenig, K.M.; Rode, L.M.; Neill, L., Entz, T. and Mir, Z. 2001. Effects of dietary sunflower seed oil on rumen protozoa population and tissue concentration of conjugated linoleic acid in sheep. Small Rumin Res, 41: 215-227.

Jenkins, T.C. 1993. Lipid metabolism in the rumen. J Dairy Sci, 76: 3851-3863.

Jekins, T.C.; Wallace, R.J.; Moate, P.J. and Mosley, E.E. 2008. Board-invited review: Recentadvances in biohydrogenation of unsaturated fatty acids within the rumen microbial ecosystem. J Anim Sci, 86: 397-412.

Jerónimo, E.; Alves, S.P.; Prates, J.A.M.; SantosSilva, J. and Bessa, R.J.B. 2009. Effect of dietary replacement of sunflower oil with linseed oil on intramuscular fatty acids of lamb meat. Meat Sci, 83: 499-505.

Jonnalagada, S.S.; Mustad, V.A.; Yu, S.; Etherton, T.D. and Kris-Etherton, P.M. 1996. Effects of individual fatty acids on chronic diseases. Nutrit Today, 31: 90-106.

Joy, M.; Ripoll, G.; Molino, F.; Dervishi, E. and Álvarez-Rodríguez, J. 2012. Influence of the type of forage supplied to ewes in pre-and post-partum periods on the meat fatty acids of suckling lambs. Meat Sci, 90: 775-782.

Karami, M.; Ponnampalam, E.N. and Hopkins, D.L. 2013. The effect of palm oil or canola oil on feedlot performance, plasma and tissue fatty acid profile and meat quality in goats. Meat Sci, doi: 10.1016/j.meatsci.2013.02.004.

Kennelly, J.J. 1996. The fatty acid composition of milk fat as influenced by feeding oilseeds. Anim Feed Sci Technol, 60: 137-152.

Kitessa, S.M.; Williams, A.; Gulati, S.; Boghossian, V.; Reynolds, J. and Pearce, K.L. 2009. Influence of duration of supplementation with ruminally protected linseed oil on the fatty acid composition of feedlot lambs. Anim Feed Sci Technol, 151: 228-239.

Kozloski, G.M. 2002. Bioquímica dos ruminantes. Santa Maria. $1^{\text {a }}$ ed. UFSM. 140 pp.

Lanza, M.; Bella, M.; Priolo, A.; Barbagallo, D.; Galofaro, V. and Landi, C. 2006. Lamb meat quality as affected by natural or artificial milk feeding regime. Meat Sci, 73: 313-318.

Lee, J.H.; Waller, J.C.; Yilmaz, Y. and Melton, S.L. 2007. Effect of feeding rumen-protected dietary protein-oil supplements on fatty acid composi- 


\section{DIFERENTES FONTES DE GORDURA SOBRE A MODULAÇÃO DO PERFIL DE ÁCIDOS}

tion and a-tocopherol content of blood serum and muscle lipids of lambs. Small Rumin Res, 72: 101-110.

Leite, L.C. 2006. Perfil de ácidos graxos do leite e metabolismo de lipídios no rúmen de vacas recebendo dietas com alto ou baixo teor de concentrado e óleo de soja ou de peixe. Tese de doutorado. Escola Superior de Agricultura Luiz de Queiroz. Piracicaba. 97 pp.

Lima, F.E.L.; Menezes, T.N.; Tavares, M.P.; Szarfarc, S.C. e Fisberg, R.M. 2000. Ácidos graxos e doenças cardiovasculares: uma revisão. Rev Nutr, 13: 73-80.

Lima Júnior, D.M.; Monteiro, P.B.S.; Rangel, A.H.N.; Urbano, S.A. e Maciel, M.V. 2011. Alimentos funcionais de origem animal. Rev VerdeAgroecologia Desenvolv Sustent, 6: 30-40.

López, S.E. e López, J. 2005. Suplementação lipídica para vacas leiteiras. Pesq Agropec Gaúcha, 11: 103-112.

Luciano, G.; Pauselli, M.; Servili, M.; Mourvaki, E.; Serra, A.; Monaham, F.J.; Lanza, M.; Priolo, A.; Zinnai, A. and Mele, M. 2013. Dietary olive cake reduces the oxidation of lipids, including cholesterol, in lamb meat enriched in polyunsaturated fatty acids. Meat Sci, 93: 703-714.

Lurueña-Martínez, M.A.; Palacios, C.; VivarQuintana, A.M. and Revilla, I. 2010. Effect of the addition of calcium soap to ewes' diet on fatty acid composition of ewe milk and subcutaneous fat of suckling lambs reared on ewe milk. Meat Sci, 84: 677-683.

Madruga, M.S.; Araújo, W.O.; Sousa, W.H.; Cézar, M.F.; Galvão, M.S. e Cunha, M.G.G. 2006. Efeito do genótipo e do sexo sobre a composição química e o perfil de ácidos graxos da carne de cordeiro. Rev Bras Zootecn, 35: 1838-1844.

Madruga, M.S.; Galvão, M.S.; Costa, R.G.; Beltrão, S.E.S.; Santos, N.M.; Carvalho, F.M. e Viaro, V.D. 2008a. Perfil aromático e qualidade química da carne de caprinos Saanen alimentados com diferentes níveis de concentrado. Rev Bras Zootecn, 37: 936-943.

Madruga, M.S.; Vieira, T.R.L.; Cunha, M.G.G.; Pereira Filho, J.M.; Queiroga, R.C.R.E. e Sousa, W.H. 2008b. Efeito de dietas com níveis crescentes de caroço de algodão integral sobre a composição química e o perfil de ácidos graxos da carne de cordeiros Santa Inês. Rev Bras Zootecn, 37: 1496-1502.
Madruga, M.S.; Narain, N.; Souza, J.G. and Costa, R.G. 2001. Castration and slaughter age effects on fat componentes of mestiço goat meat. Small Rumin Res, 42: 77-82.

Mahgoub, O.; Khan, A.J.; Al-Maqbaly, R.S.; AlSabahi, J.N.; Annamalai, K. and Al-Sakry, N.M. 2002. Fatty acid composition of muscle and fat tissues of Omani Jebel Akhdar goats of different sexes and weights. Meat Sci, 61: 381-387.

Mahgoub, O. and Lodge, G. A. 1998. A comparative study on growth, body composition and carcass tissue distribution in Omani sheep and goats. $J$ Agricul Sci, 131: 329-339.

Maia, M.R.G. 2010. Microrganismos e factores alimentares que afectam a bioidrogenação e a produção de isómeros conjugados do ácido linoleico no ecossistema ruminal. Tese de doutorado. Faculdade de Medicina Veterinária-Universidade Técnica de Lisboa. Lisboa. 209 pp.

Maia, M.O.; Costa, F.S.; Susin, I.; Rodrigues, G.H.; Ferreira, E.M.; Pires, A.V.; Gentil,. R.S. e Mendes, C.Q. 2012. Efeito do genótipo sobre a composição química e o perfil de ácidos graxos da carne de borregas. Rev Bras Zootecn, 41: 986-992.

Manso, T.; Bodas, R.; Castro, T.; Jimeno, V.; Mantecon, A.R. 2009. Animal performance and fatty acid composition of lambs fed with different vegetable oils. Meat Sci. 83: 511-516.

Marinova, P.; Banskalieva, V.; Alexandrov, S.; Tzvetkova, V. and Stanchev, H. 2001. Carcass composition and meat quality of kids fed sunflower oil supplemented diet. Small Rumin Res, 42: 219-227.

Menezes, L.F.G.; Kozloski, G.V.; Restle, J.; Deschamps, F.C.; Brondani, I.L.; Santos, A.P. e Fiamoncini, J. 2006. Perfil de ácidos graxos de cadeia longa e qualidade da carne de novilhos terminados em confinamento com diferentes níveis de monensina sódica na dieta. Ciên Rural, 36: 186-190.

Mushi, D.E.; Thomassen, M.S.; Kifaro, G.C. and Eik, L.O. 2012. Fatty acid composition of minced meat, longissimus muscle and omental fat fromSmall East African goats finished on different levels of concentrate supplementation. Meat Sci, 86: 337-342.

Najafi, M.H.; Zeinoaldini, S.; Ganjkhanlou, M.; Mohammadi, H.; Hopkins, D.L. and Ponnampalam, E.N. 2012. Performance, carcass traits, muscle fatty acid composition and meat sensory properties 


\section{URBANO, FERREIRA, OLIVEIRA, LIMA JÚNIOR E ANDRADE}

of male Mahabadi goat kids fed palm oil, soybean oil or fish oil. Meat Sci, 92: 848-854.

Nassu, R.T.; Gonçalves, L.A.G. e Beserra, F.J. 2002. Efeito do teor de gordura nas características químicas e sensoriais de embutido fermentado de carne de caprinos. Pesq Agropec Bras, 37: 1169-1173.

Nelson, D. L. e Cox, M. 2002. Lehninger - Princípios de Bioquímica. $3^{\mathrm{a}}$ ed. Editora Sarvier. São Paulo. 1009 pp.

Neves, C.A. 2007. Modulação do perfil de ácidos graxos do leite de vacas por meio da adição do lignosulfonato e da extrusão do grão de canola. Tese de doutorado, Universidade Estadual de Maringá. Maringá. 87 pp.

Nudda, A.; Palmquist, D.L.; Battacone, G.; Fancellu, S.; Rassu, S.P.G. and Pulina, G. 2008. Relationships between the contents of vaccenic acid, CLA and $n-3$ fatty acids of goat milk and the muscle of their suckling kids. Livest Sci, 118: 195-203.

Nuernberg, K.; Fischer, A.; Nuernberg, G.; Ender, K. and Dannenberger, D. 2008. Meat quality and fatty acid composition of lipids in muscle and fatty tissue of Skudde lambs fed grass versus concentrate. Meat Sci, 74: 279-283.

Nussio, L.G.; Campos, F.P. e Lima, M.L.M. 2006. Metabolismo de carboidratos estruturais. In: Berchielli, T.T.; Pires, A.V.; Oliveira, S.G. Nutrição de Ruminantes. $1^{\text {a }}$ ed. Funep. Jaboticabal. 583 pp.

Nute, G.R.; Richardson, R.I.; Wood, J.D.; Hughes, S.I.; Wilkinson, R.G.; Cooper, S.L. and Sinclair, L.A. 2007. Effect of dietary oil source on the flavour and the colour and lipid stability of lamb meat. Meat Sci, 77: 547-555.

Palmquist, D.L. e Mattos, W.R.S. 2006. Metabolismo de lipídeos. In: Berchielli, T.T.; Pires, A.V.; Oliveira, S.G. Nutrição de Ruminantes. $1^{\text {a }}$ ed. Funep. Jaboticabal. 583 pp.

Peng, Y.S.; Brown, M.A.; Wu, J.P. and Liu, Z. 2010. Different oilseed supplements alter fatty acid composition of different adipose tissues of adult ewes. Meat Sci, 85: 542-549.

Perez, J.R.O.; Bressan, M.C.; Bragagnolo, N.; Prado, O.V.; Lemos, A.L.S.C. e Bonagurio, S. 2002. Efeito do peso ao abate de cordeiros santa inês e bergamácia sobre o perfil de ácidos graxos, colesterol e propriedades químicas. Ciên Tecnol Alim, 22: 11-18.

Petrova, Y.; Banskalieva, V. and Dimov, V. 1994. Effect of feeding on distribution of fatty acids at Sn_2 position in triacylglycerols of different adipose tissues in lambs. Small Rumin Res, 13: 263-267.

Ponnampalam, E.N.; Sinclair, A.J.; Egan, A.R.; Blakeley, S.J. and Leury, B.J. 2001. Effect of diets containing $n-3$ fatty acids on muscle long-chain n-3 fatty acid content in lambs fed low- and mediumquality roughage diets. J Anim Sci, 79: 698-706. Ponnampalam, E.N.; Sinclair, A.J.; Egan, A.R.; Ferrier, G.R. and Leury, B.J. 2002a. Dietary manipulation of muscle long-chain omega-3 and omega- 6 fatty acids and sensory properties of lamb meat. Meat Sci, 60: 125-132.

Ponnampalam, E.N.; Sinclair, A.J.; Hosking, B.J. and Egan, A.R. 2002b. Effects of dietary lipid type on muscle fatty acid composition, carcass leanness, and meat toughness in lambs. J Anim Sci, 80: 628-636.

Qwele, K.; Hugo, A.;Oyedemi, S.O.; Moyo, B.; Masika, P.J. and Muchenje, V. 2013. Chemical composition, fatty acid content and antioxidant potential of meat from goats supplemented with Moringa(Moringa oleifera) leaves, sunflower cake and grass hay. Meat Sci, 93: 455-462.

Raes, K.; Smet, S. De. and Demeyer, D. 2004. Effect of dietary fatty acids on incorporation of long chain polyunsaturated fatty acids and conjugated linoleic acid in lamb, beef and pork meat: a review. Anim Feed Sci Technol, 113: 199-221.

Relling, A. y Mattioli, G. 2003. Fisiología Digestiva y Metabólica de los Rumiantes. Fac. Ciencias Veterinarias. Argentina: Universidad Nacional de La Plata. Disponível http://ecaths1.s3.amazonaws. com/catbioquimicavet/fisio\%20dig\%20rumiantes. pdf (01/02/2013).

Rioux, V. and Legrand, P. 2007. Saturated fatty acids: simple molecular structures with complex cellular functions. Curr Opin Clin Nutr Metab Care, 10: 752-775.

Rizzi, L.; Simioli, M.; Sardi, L. and Monetti, P.G. 2002. Carcass quality, meat chemical and fatty acid composition of lambs feed diets containing extruded soybeans and sunflower seeds. Anim Feed Sci Technol, 97: 103-114.

Santos, F.L.; Silva, M.T.C.; Lana, R.P.; Brandão, S.C.C.; Vargas, L.H. e Abreu, L.R. 2001. Efeito da suplementação de lipídios na ração sobre a produção de ácido linoléico conjugado (CLA) e a composição da gordura do leite de vacas. Rev Bras Zootecn, 30: 1931-1938. 


\section{DIFERENTES FONTES DE GORDURA SOBRE A MODULAÇÃO DO PERFIL DE ÁCIDOS}

Santos Filho, J.M.; Morais, S.M.; Beserra, F.J. e Zapata, J.F.F. 2001. Lipídios em carnes de animais utilizados para consumo humano: uma revisão. Ciên Anim, 11: 87-100.

Santos-Silva, J.; Mendes, I.A.; Portugal, P.V.e Bessa, R.J.B. 2004. Effect of particle size and soybean oil supplementation on growth performance, carcass and meat quality and fatty acid composition of intramuscular lipids of lambs. Livest Prod Sci, 90: 79-88.

Schmid, A.; Collomb, M.; Sieber, R. and Bee, G. 2006. Conjugated linoleic acid in meat and meat products: A review. Meat Sci, 73: 29-41.

Tejeda, J.F.; Peña, R.E. and Andrés, A.I. 2008. Effect of live weight and sex on physico-chemical and sensorial characteristics of Merino lamb meat. Meat Sci, 80: 1061-1067.

Tshabalala, P.A.; Strydom, P.E.; Webb, E.C. and Kock, H.L. de. 2003. Meat quality of designated South African indigenous goat and sheep breeds. Meat Sci, 65: 563-570.

Valadares Filho, S.C. e Pina, D.S. 2006. Fermentação ruminal. In: Berchielli, T.T.; Pires, A.V.; Oliveira, S.G. Nutrição de Ruminantes. $1^{\mathrm{a}}$ ed. Funep. Jaboticabal. 583 pp.

Valinote, A.C.; Nogueira Filho, J.C.M.; Leme, P.R.; Luz e Silva, S. e Cunha, J.A. 2005. Fontes de Lipídeos e Monensina na Alimentação de Novilhos Nelore e sua Relação com a População de Protozoários Ciliados do Rúmen. Rev Bras Zootecn, 4: 1418-1423.

Valsta, L.M.; Tapanainen, H. and Männistö, S. 2005. Meat fats in nutrition. Meat Sci, 70: 525-530.

Van Soest, P.J. 1994. Nutritional ecology of the ruminant. Cornell University. Ithaca. $479 \mathrm{pp}$.

Valsta, V.; Makkar, H.P.S.; Mele, M. and Priolo, A. 2009. Ruminal biohydrogenation as affected by tannins in vitro. Brit J Nutrit, 102: 82-92.

Wang, J.H.; Zhu, B.H.; Song, M.K. and Choi, Y.J. 2005. Effect of monensin, fish oil or their combination on in vitro fermentation and conjugated linoleic acid (CLA) production by ruminal bacteria. Anim Feed Sci Technol, 120: 341-349.

Wasowska, I.; Maia, M.R.G.; Niedzwiedzka, K.M.; Czauderna, M.; Ribeiro, J.M.C.R.; Devillard, E.; Shingfield, K.J. and Wallace, R.J. 2006. Influence of fish oil on ruminal biohydrogenation of C18 unsaturated fatty acids. Brit J Nutr, 95: 1199-1211.

Wattiaux, M. A. and Grummer, R.R. 2004. Lipid metabolism in dairy cows. In: Dairy Essentials, Babcock Institute for International Dairy Research and Development, University of Wisconsin-Madison. http://babcock.cals.wisc.edu/downloads/de/04. en.pdf (01/02/2013).

Webb, E.C. and O'Neill, H.A. 2008. The animal fat paradox and meat quality. Meat Sci, 80: 28-36.

Wood, J.D.; Enser, M.; Fisher, A.V.; Nute, G.R.; Richardson, R.I. and Sheard, P.R. 1999. Manipulating meat quality and composition. Proceedings Nutrit Soc, 58: 363-370.

Wood, J.D.; Richardson, R.I.; Nute, G.R.; Fisher, A.V.; Campo, M.M. and Kasapidou, E. 2004. Effects of fatty acids on meat quality: A review. Meat Sci, 66: 21-32.

Wood, J.D.; Enser, M.; Fisher, A.V.; Nute, G.R.; Sheard, P.R.; Richardson, R.I.; Hughes, S.I. and Whittington, F.M. 2008. Fat deposition, fatty acid composition and meat quality: Areview. Meat Sci, 78: 343-358.

Woods, V.; Fearon, A.M. 2009. Dietary sources of unsaturated fatty acids for animals and their transfer into meat, milk and eggs: Areview. Livest Sci, 126: 1-20.

Zapata, J.F.F.; Nogueira, C.M.; Seabra, L.M. J.; Barros, N.N. e Borges, A.S. 2001. Composição centesimal e lipídica da carne de ovinos do nordeste brasileiro. Ciên Rural, 31: 691-695.

Zeola, N.M.B.; Silva Sobrinho, A.G.; Gonzaga Neto, S. e Marques, C.A.T. 2004. Composição centesimal da carne de cordeiros submetidos a dietas com diferentes teores de concentrado. Ciên Rural, 34: 253-257. 